\title{
1,3-Diene Polymerization Mediated by Homoleptic Tetramethylaluminates of the Rare-Earth Metals
}

\author{
Christoph O. Hollfelder, Lars N. Jende, Dominic Diether, Theresa Zelger, Rita Stauder, \\ Cäcilia Maichle-Mössmer and Reiner Anwander* (iD \\ Institut für Anorganische Chemie, Eberhard-Karls-Universität Tübingen, 72076 Tübingen, Germany; \\ christoph.hollfelder@anorg.uni-tuebingen.de (C.O.H.); lars.jende@univ-rennes1.fr (L.N.J.); \\ dominic.diether@anorg.uni-tuebingen.de (D.D.); theresa.zelger@student.uni-tuebingen.de (T.Z.); \\ rita.stauder@student.uni-tuebingen.de (R.S.); caecilia.maichle-moessmer@uni-tuebingen.de (C.M.-M.) \\ * Correspondence: reiner.anwander@uni-tuebingen.de; Tel.: +49-7071-29-72069
}

Received: 30 December 2017; Accepted: 23 January 2018; Published: 3 February 2018

\begin{abstract}
During the past two decades homoleptic tetramethylaluminates of the trivalent rare-earth metals, $\operatorname{Ln}\left(\mathrm{AlMe}_{4}\right)_{3}$, have emerged as useful components for efficient catalyst design in the field of 1,3-diene polymerization. Previous work had focused on isoprene polymerization applying $\mathrm{Ln}\left(\mathrm{AlMe}_{4}\right)_{3}$ precatalysts with $\mathrm{Ln}=\mathrm{La}, \mathrm{Ce}, \mathrm{Pr}, \mathrm{Nd}, \mathrm{Gd}$ and $\mathrm{Y}$, in the presence of $\mathrm{Et}_{2} \mathrm{AlCl}$ as an activator. Polymerizations employing $\operatorname{Ln}\left(\mathrm{AlMe}_{4}\right)_{3}$ with $\mathrm{Ln}=\mathrm{La}, \mathrm{Y}$ and $\mathrm{Nd}$ along with borate/borane co-catalysts $\left[\mathrm{Ph}_{3} \mathrm{C}\right]\left[\mathrm{B}\left(\mathrm{C}_{6} \mathrm{~F}_{5}\right)_{4}\right],\left[\mathrm{PhNMe}{ }_{2} \mathrm{H}\right]\left[\mathrm{B}\left(\mathrm{C}_{6} \mathrm{~F}_{5}\right)_{4}\right]$ and $\left[\mathrm{B}\left(\mathrm{C}_{6} \mathrm{~F}_{5}\right)_{3}\right]$ were mainly investigated for reasons of comparison with ancillary ligand-supported systems (cf. half-sandwich complexes). The present study investigates into a total of eleven rare-earth elements, namely $\mathrm{Ln}=\mathrm{La}$, Ce, Pr, Nd, Gd, Tb, Dy, Ho, Y, Er and Lu. A full overview on the polymerization behavior of $\mathrm{Ln}\left(\mathrm{AlMe}_{4}\right)_{3}$ in the presence of perfluorinated borate/borane cocatalysts and $\mathrm{R}_{2} \mathrm{AlCl}$-type activators $(\mathrm{R}=\mathrm{Me}, \mathrm{Et})$ is provided, probing the monomers isoprene and 1,3-butadiene (and preliminary ethylene). Virtually complete cis-1,4-selectivities are obtained for several catalyst/cocatalyst combinations (e.g., $\mathrm{Gd}\left(\mathrm{AlMe}_{4}\right)_{3} / \mathrm{Me}_{2} \mathrm{AlCl},>99.9 \%$ ). Insights into the 'black box' of active species are obtained by indirect observations via screening of pre-reaction time and cocatalyst concentration. The microstructure of the polydienes is investigated by combined ${ }^{1} \mathrm{H} /{ }^{13} \mathrm{C}$ NMR and ATR-IR spectroscopies. Furthermore, the reaction of $\left[\mathrm{LuMe}_{6}\left(\mathrm{Li}(\mathrm{thf})_{\mathrm{X}}\right)_{3}\right]$ with $\mathrm{AlMe}_{3}$ has been applied as a new strategy for the efficient synthesis of $\mathrm{Lu}\left(\mathrm{AlMe}_{4}\right)_{3}$. The solid-state structures of $\mathrm{Gd}\left(\mathrm{AlMe}_{4}\right)_{3}$ and $\mathrm{Tb}\left(\mathrm{AlMe}_{4}\right)_{3}$ are reported.
\end{abstract}

Keywords: lanthanide; rare-earth elements; synthetic rubber; 1,3-diene polymerization; alkyl; aluminum; tetramethylaluminate

\section{Introduction}

Since its discovery and development in the 1950s and 1960s, Ziegler-Natta polymerization catalysis has undergone various empirical optimizations regarding the composition of the catalyst mixtures applied [1-3]. While the actual active (bimetallic) catalysts/sites have remained elusive and are subject of ongoing research, the properties of the industrially fabricated polymer products have been tailored by choice of component concentrations and additives [1,4-6].

'Ziegler Mischkatalysatoren' gain their exceptional reactivity through the cooperativity of a transition metal component and an organoaluminum(magnesium) activator [1-5]. Industrial 1,3-diene polymerization processes also take advantage of Ziegler-type catalysts and ternary mixtures like carboxylate-based $\mathrm{Nd}\left(\mathrm{O}_{2} \mathrm{CR}\right)_{3} / \mathrm{Et}_{3} \mathrm{Al}_{2} \mathrm{Cl}_{3} / i \mathrm{Bu}_{2} \mathrm{AlH}(1: 1: 8)$ or $\mathrm{Nd}\left(\mathrm{O}_{2} \mathrm{CR}\right)_{3} / \mathrm{Et}_{3} \mathrm{Al}_{2} \mathrm{Cl}_{3} / \mathrm{Al} \mathrm{Bu}_{3}$ (1:1:30) [6] proved superior to ternary 'no-less-complex' d-transition metal-based catalyst systems in terms of activity and stereospecificity issues [6-9]. On the other hand, thermally stable homoleptic 
tetramethylaluminates of the rare-earth metals, $\operatorname{Ln}\left(\mathrm{AlMe}_{4}\right)_{3}$, feature a preset heterobimetallic arrangement, per se simplifying the assessment of structure reactivity relationships (ternary versus binary catalyst system) [4,10-13]. Especially, when applying dialkylaluminum chlorides as cocatalysts/activators, complexes $\operatorname{Ln}\left(\mathrm{AlMe}_{4}\right)_{3}$ display one of the closest possible modelling approaches to in situ generated Ziegler-type systems [14,15]. Previous studies on the use of homoleptic $\operatorname{Ln}\left(\mathrm{AlMe}_{4}\right)_{3}$ as precatalysts for isoprene polymerization have been reported on several occasions, some of them even out of the main spotlight of the respective article, so that they are easily missed [11-13,16-18]. Accordingly, $\mathrm{Et}_{2} \mathrm{AlCl}$ has been applied as an activator for $\mathrm{Ln}\left(\mathrm{AlMe}_{4}\right)_{3}(\mathrm{Ln}=\mathrm{La}, \mathrm{Ce}, \mathrm{Pr}, \mathrm{Nd}, \mathrm{Gd}$ and Y) $[11-13,16,17]$. Moreover, investigations using borate and borane cocatalysts $\left[\mathrm{Ph}_{3} \mathrm{C}\right]\left[\mathrm{B}\left(\mathrm{C}_{6} \mathrm{~F}_{5}\right)_{4}\right](\mathrm{A})$, $\left[\mathrm{PhNMe}_{2} \mathrm{H}\right]\left[\mathrm{B}\left(\mathrm{C}_{6} \mathrm{~F}_{5}\right)_{4}\right](\mathbf{B})$ and $\left[\mathrm{B}\left(\mathrm{C}_{6} \mathrm{~F}_{5}\right)_{3}\right](\mathbf{C})$ have been performed for reasons of comparison $[13,18]$. Herein, we present a full account of the polymerization performance of complexes $\operatorname{Ln}\left(\mathrm{AlMe}_{4}\right)_{3}$ giving consideration to eleven different rare-earth metals ( $\mathrm{La}, \mathrm{Ce}, \mathrm{Pr}, \mathrm{Nd}, \mathrm{Gd}, \mathrm{Tb}, \mathrm{Dy}, \mathrm{Ho}, \mathrm{Y}$, Er and $\mathrm{Lu}$ ), as well as borate (A, B)/borane cocatalysts (C) and $\mathrm{R}_{2} \mathrm{AlCl}$ activators $(\mathrm{R}=\mathrm{Me}(\mathrm{D}), \mathrm{Et}(\mathrm{E}))$. The redox-active rare-earth elements $\mathrm{Sm}, \mathrm{Eu}$ and $\mathrm{Yb}$, favoring the formation of divalent alkylaluminate species [19], are not included in the present study. The active species involved in 1,3-diene polymerization reactions are investigated indirectly by screening of the polymerizations at various conditions applying $\mathrm{Nd}\left(\mathrm{AlMe}_{4}\right)_{3}$.

Furthermore, a new protocol for efficiently synthesizing homoleptic methylaluminates of the smaller lanthanides, e.g., $\mathrm{Lu}\left(\mathrm{AlMe}_{4}\right)_{3}$, is introduced and active catalyst systems derived from $\mathrm{Nd}\left(\mathrm{AlMe}_{4}\right)_{3}$ are initially probed for the polymerization of ethylene.

\section{Results and Discussion}

\subsection{Catalyst Systems}

\subsubsection{Precatalyst Synthesis and Structural Characterization}

Homoleptic tris(tetramethylaluminate)s of the rare-earth elements are routinely accessible in a two-step synthesis starting from the tetrahydrofuran (thf) adducts of the commercially available chlorides. Salt metathesis with lithium dimethylamide in THF gives ate complexes [ $\left.\mathrm{Ln}\left(\mathrm{NMe}_{2}\right)_{3}(\mathrm{LiCl})_{3}\right]$ $\left(1^{\mathrm{Ln}}\right)$ which are treated subsequently with an excess of $\mathrm{AlMe}_{3}$ in $n$-hexane to afford $\mathrm{Ln}\left(\mathrm{AlMe}_{4}\right)_{3}$ $\left(2^{\text {Ln }} ; \mathrm{Ln}=\mathrm{La}[11,12], \mathrm{Ce}[12,20], \operatorname{Pr}[12], \mathrm{Nd}\right.$ [12,21], Gd [11], Tb (this work), Dy [22], Ho [12],

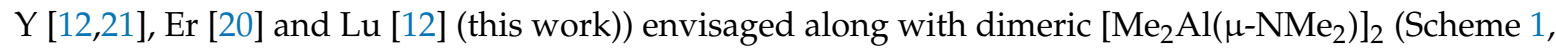
route I) $[4,11-13,20-23]$.

$$
\begin{aligned}
& \text { I } \mathrm{LnCl}_{3}(\mathrm{thf})_{\mathrm{x}}+3 \mathrm{LiNMe}_{2} \underset{\mathrm{rt}, 18 \mathrm{~h}}{\stackrel{\mathrm{THF}}{\longrightarrow}}\left[\operatorname{Ln}\left(\mathrm{NMe}_{2}\right)_{3}(\mathrm{LiCl})_{3}\right] \mathbf{1}^{\mathrm{Ln}}
\end{aligned}
$$

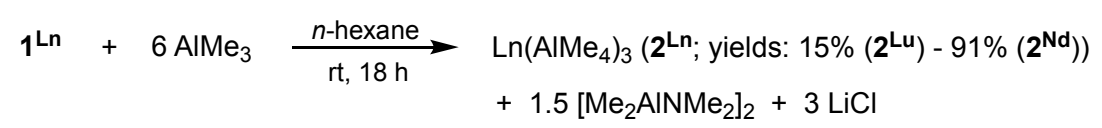

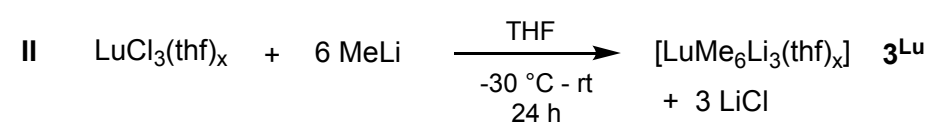

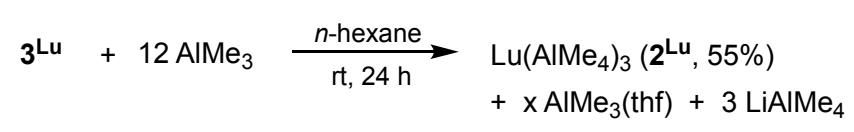

Scheme 1. Synthesis of homoleptic rare-earth metal(III) tetramethylaluminates $\left(\mathrm{Ln}=\mathrm{La}\left(2^{\mathrm{La}}\right), \mathrm{Ce}\left(2^{\mathrm{Ce}}\right)\right.$, $\operatorname{Pr}\left(2^{\mathrm{Pr}}\right), \mathrm{Nd}\left(2^{\mathrm{Nd}}\right), \mathrm{Gd}\left(2^{\mathrm{Gd}}\right), \operatorname{Tb}\left(2^{\mathrm{Tb}}\right), \operatorname{Dy}\left(2^{\mathrm{Dy}}\right), \operatorname{Ho}\left(2^{\mathrm{H} \circ}\right), \mathrm{Y}\left(2^{\mathrm{Y}}\right), \operatorname{Er}\left(2^{\mathrm{Er}}\right)$ and $\left.\operatorname{Lu}\left(2^{\mathrm{Lu}}\right)\right)$. 
The major drawback of amide elimination protocol $\mathbf{I}$ is that the $\mathrm{AlMe}_{3}$-mediated $\left[\mathrm{NMe}_{2}\right] \rightarrow$ [ $\mathrm{AlMe}_{4}$ ] exchange in $n$-hexane provides decent yields only for the larger rare-earth metal ions [12]. In case of the smallest rare-earth metal, lutetium, purification requires subsequent sublimation allowing isolation of the desired $\mathrm{Lu}\left(\mathrm{AlMe}_{4}\right)_{3}$ only in ca. $15 \%$ yield [24]. Therefore, a new synthesis approach was developed, based on the trianionic hexamethylate ate complexes $\left[\operatorname{LnMe}_{6}\left\{\operatorname{Li}(\operatorname{Do})_{x}\right\}_{3}\right]$ (Do = tetramethylethylenediamine (tmeda), dimethoxyethane (dme), thf, diethyl ether) reported by Schumann et al. [25-27]. Treatment of $\left[\mathrm{LuMe}_{6}\left\{\mathrm{Li}(\mathrm{thf})_{\mathrm{x}}\right\}_{3}\right]$ with excess of $\mathrm{AlMe}_{3}$ produced the homoleptic methylaluminate complex $\mathrm{Lu}\left(\mathrm{AlMe}_{4}\right)_{3}\left(2^{\mathrm{Lu}}\right)$ in moderate crystalline yields (Scheme 1, route II). The side-products $\mathrm{LiAlMe}_{4}$ and donor-coordinated $\mathrm{AlMe}_{3}$ can easily be removed via filtration and evaporation, respectively. The absence of ate complex formation is due to the high steric saturation of the metal center by the tetramethylaluminate moieties, which show additional agostic or coordinative interactions only for the larger rare-earth metal ions [12].

The solid-state structures of complexes $2^{\mathrm{Ln}}$ employed in this study were known to all rare-earth elements except gadolinium and terbium. Putative $2^{\mathrm{Sc}}, 2^{\mathrm{Pm}}$, and $\mathbf{2}^{\mathrm{Eu}}$ (and hence their crystal structures) are not accessible due to reasons of stereoelectronic mismatch (Sc), radioactivity issues (Pm), and redox instability (Eu), respectively. Since complex $2^{\mathrm{Gd}}$ gave a catalyst system of exceptional performance, its crystal structure was determined (Figure 1a, Table S4.1, Supplementary Materials). To complete the series of accessible crystal structures we include also the data of $2^{\mathrm{Tb}}$ (Figure S4.1, Table S4.1, Supplementary Materials).

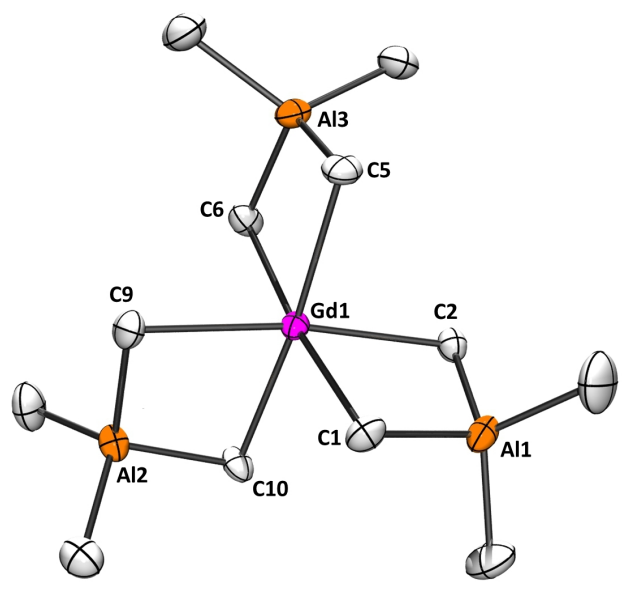

(a)

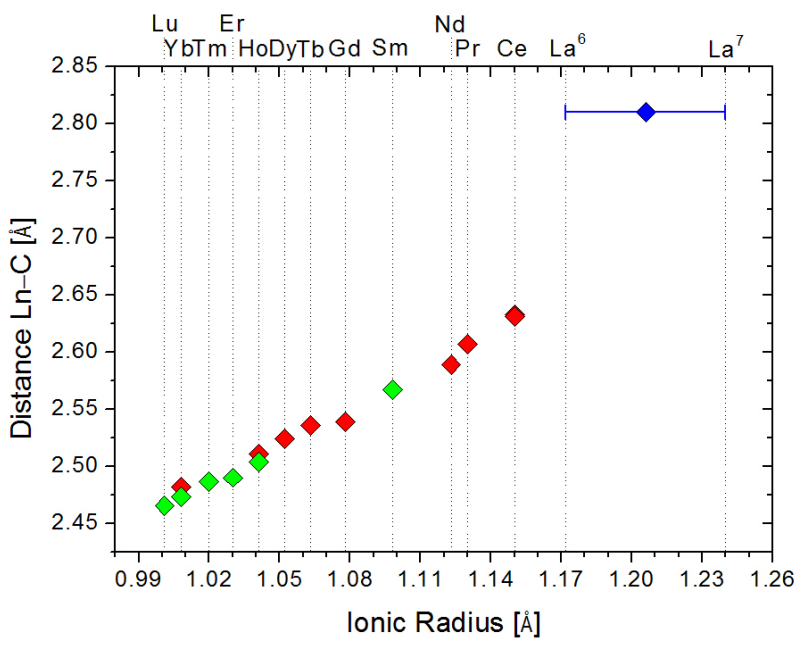

(b)

Figure 1. (a) ORTEP view of one of two individuals in the unit cell of $\mathbf{2}^{\mathrm{Gd}}$. Atoms are represented by atomic displacement ellipsoids at the 50\% level. Hydrogen atoms are omitted for clarity. Selected distances $(\AA)$ and angles (deg): Gd1—C1 2.543(4), Gd1—C2 2.542(4), Gd1—C5 2.550(4), Gd1-C6 2.529(4), Gd1—C9 2.529(4), Gd1-C10 2.552(4), average Gd1-CX (X=1, 2, 5, 6, 9, 10) 2.539, Al1-C1, 2.082(4), Al1-C2, 2.086(4); C1-Gd1-C2 83.92(12), C1-Gd1-C5 92.43(13), C1-Gd1-C6 174.78(13), C1-Al1-C2 109.30(16). $2^{\text {Tb }}$ crystallizes isostructurally, see Section S4, Supplementary Materials. (b) Overview chart on average distances of $\mathrm{Ln}-\mathrm{C}$ vs. the ionic radii of the rare-earth metal trivalent cations according to Shannon and Prewitt $[28,29]$ with a coordination number $(\mathrm{CN})$ of 6 . In case of $2^{\text {La }}$, featuring $\eta^{3}$-coordination of one of the tetramethylaluminate moieties [12], the span of $\mathrm{CN}=6$ to $\mathrm{CN}=7$ is given. Crystal structures in space group $P 2_{1} / c$ are represented by red symbols, those in $\mathrm{C} 2 / \mathrm{c}$ by green symbols and that of $2^{\mathrm{La}}$, not following the general motifs due to the coordination of one additional methyl group and crystallizing in $P 2_{1} / n$, by a blue symbol. Data are taken from references [12,19-22] and this work. 
Figure $1 \mathrm{~b}$ gives an overview on the $\mathrm{Ln}-\mathrm{C}$ distances of all known $2^{\mathrm{Ln}}$, thus displaying the first comprehensive structural data compilation on rare-earth metal alkyl complexes of the same type. While the smaller lanthanides show a tendency towards crystallization as blocks in space group $C 2 / c$ (green symbols) the larger representatives crystallize as needles in space group $P 2_{1} / c$ (red symbols, two individuals per unit cell). The largest rare-earth metal center lanthanum adopts a different molecular structure (7- instead of 6-coordinate La(III) centers; space group $P 2_{1} / n$ [12], marked in blue). The structures of $2^{\mathrm{Gd}}$ and $2^{\mathrm{Tb}}$ added to the series in this study (see Section S4, Supplementary Materials) are part of the first group and show the expected $\mathrm{Ln}-\mathrm{C}$ distances to fit the linear increase with the ionic radii (Figure $1 b$ ). For $\mathrm{Ln}=\mathrm{Ho}$ and $\mathrm{Yb}$ both crystal habits/modifications exist and were achieved by applying different crystallization parameters $[19,20]$. In case of $\mathrm{Ln}=\mathrm{Ce}$, two modifications in space group $P 2_{1} / c$ are known $[19,20]$.

\subsubsection{Activation by Cationizing Cocatalysts}

In order to activate the precatalysts for diene polymerization, the five most common cationizing agents were applied. Organoperfluoroborates and -borane $\left[\mathrm{Ph}_{3} \mathrm{C}\right]\left[\mathrm{B}\left(\mathrm{C}_{6} \mathrm{~F}_{5}\right)_{4}\right]$ (A), $\left[\mathrm{PhNMe}{ }_{2} \mathrm{H}\right]\left[\mathrm{B}\left(\mathrm{C}_{6} \mathrm{~F}_{5}\right)_{4}\right](\mathbf{B})$ and $\mathrm{B}\left(\mathrm{C}_{6} \mathrm{~F}_{5}\right)_{3}(\mathrm{C})$, respectively, cationize neutral homoleptic complexes $2^{\text {Ln }}$ following ligand abstraction $(\mathbf{A}, \mathbf{C})$ and protonolysis (B) pathways (Scheme 2, upper part) [30-32]. Similar species were suggested to form in the silylamide-based catalyst system $\mathrm{Nd}\left[\mathrm{N}\left(\mathrm{SiMe}_{3}\right)_{2}\right]_{3} / \mathbf{B} / \mathrm{AliBu}_{3}(1: 1: 10)$ employed for 1,3-butadiene polymerization in heptane at $70{ }^{\circ} \mathrm{C}$ (cis:trans $=86.5: 11)$ [33].
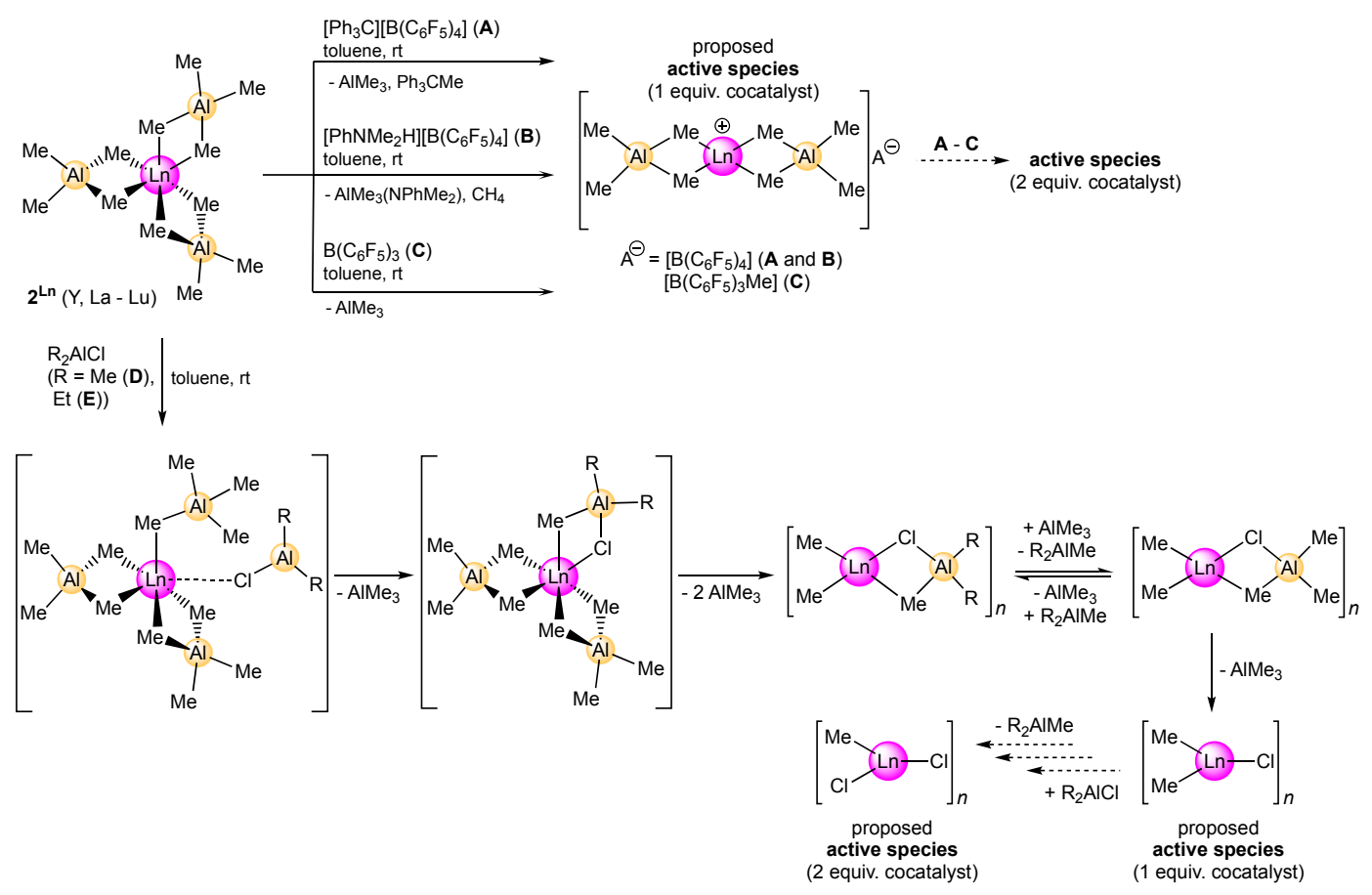

Scheme 2. Scenario of the activation of homoleptic rare-earth metal(III) tetramethylaluminates $\mathbf{2}^{\mathbf{L n}}$ by cocatalysts $\mathbf{A}-\mathbf{E}\left(\mathbf{A}=\left[\mathrm{Ph}_{3} \mathrm{C}\right]\left[\mathrm{B}\left(\mathrm{C}_{6} \mathrm{~F}_{5}\right)_{4}\right], \mathbf{B}=\left[\mathrm{PhNMe}_{2} \mathrm{H}\right]\left[\mathrm{B}\left(\mathrm{C}_{6} \mathrm{~F}_{5}\right)_{4}\right], \mathbf{C}=\mathrm{B}\left(\mathrm{C}_{6} \mathrm{~F}_{5}\right)_{3}, \mathbf{D}=\mathrm{Me}_{2} \mathrm{AlCl}\right.$, $\left.\mathbf{E}=\mathrm{Et}_{2} \mathrm{AlCl}\right)$, lower part adapted from ref. [10]. Activation side-product $\mathrm{AlMe}_{3}\left(\mathrm{NPhMe}_{2}\right)$, obtaind via activation of $\mathbf{2}^{\mathbf{L n}}$ with $\mathbf{B}$ is according to previous findings [31,32].

In contrast to cocatalysts $\mathrm{A}-\mathrm{C}, \mathrm{R}_{2} \mathrm{AlCl}$-based activators $(\mathrm{D}, \mathrm{R}=\mathrm{Me} ; \mathrm{E}, \mathrm{R}=\mathrm{Et})$ are supposed to cationize the precatalysts by formation of large, multimetallic systems. It is presumed, that $\mathrm{R}_{2} \mathrm{AlCl}$ replaces $\mathrm{AlMe}_{3}$ in the aluminate precursors and that larger clusters form by chlorido bridging, as it has been observed for lanthanide half-sandwich complexes carrying tetramethylaluminate moieties and for lanthanidocene model systems for Ziegler-Natta catalysis [4,32,34-36], as well as for lanthanide 
mixed silylamide/chloride complexes [13]. With release of $\mathrm{R}_{2}$ AlMe multimetallic species are formed (Scheme 2) $[4,13,35]$. As the precursor carries three $\left[\mathrm{AlMe}_{4}\right]^{-}$moieties, the exchange of $\mathrm{AlMe}_{3} \mathrm{vs}$. $\mathrm{R}_{2} \mathrm{AlCl}$ can happen multiple times. Temporary re-coordination of $\mathrm{R}_{2} \mathrm{AlMe}$ and therefore exchange of a methyl moiety in the final active species for $\mathrm{R}$ cannot be ruled out. This causes the presence of several distinct (cationic) clusters. As these are all assumed active species in diene polymerization with different polymerization rates, high PDI values have to be expected for the polymer products. Equilibria between clusters of different sizes could even provide enhanced complexity to these systems. It has to be mentioned, that coordination of comparably bulky substrates like monomer molecules is for all these reasons likely to have a strong impact on the structure/agglomeration of these systems. Therefore, the active initiating and propagating species might differ markedly. Interestingly, elemental analysis of the catalysts obtained from $2^{\mathrm{Nd}}$ or $\mathbf{2}^{\mathrm{Y}}$ and $\mathrm{E}$ showed very low aluminium contents $(<6 \%)$ [13], which indicates that the ratio $\mathrm{n}(\mathrm{Al}) / \mathrm{n}(\mathrm{Ln})$ in the active species is far smaller than 1 , implying the active species being close to $\left[\operatorname{LnMe}_{\mathrm{x}} \mathrm{Cl}_{\mathrm{y}}\right]_{n}(\mathrm{x}+\mathrm{y}=3)$, shown in the lower part of Scheme 2.

\subsection{Isoprene Polymerization Catalysis}

\subsubsection{Polymers Obtained at Standard Conditions}

Previous isoprene polymerization reactions applying homoleptic complexes $2^{\mathrm{Ln}}$ were routinely run for $24 \mathrm{~h}$ revealing full conversion. In order to better assess the polymerization rate, in this study, a period of only $1 \mathrm{~h}$ was chosen as standard reaction time. Prior to monomer addition, the precatalyst and 1 or 2 equiv. of the respective cocatalyst were allowed to react for $30 \mathrm{~min}$ to ensure complete activation. For further details on the polymerization procedures, see Section 3.3.

Activation by a Single Equivalent of Borate/Borane. Overviewing the polymer data obtained with precatalysts $2^{\mathrm{Ln}}$ activated by borates/borane A-C (Figure 2a-c,f-h and Figure 3a-c; Tables S1.1.1-1.1.3, Supplementary Materials) shows high yields with both 1 and 2 equiv. of the respective cocatalyst after $1 \mathrm{~h}$.

The microstructures revealed an overall increasing cis-content from $\mathrm{Ce}$ to $\mathrm{Lu}$ (from $44 \%$ to $77 \%$ (A), $44 \%$ to $78 \%$ (B) and, less steadily from $55 \%$ to $74 \%$ (C)), a decreasing trans-content (from $52 \%$ to $17 \%$ (A), $53 \%$ to $17 \%$ (B) and less steadily from $60 \%$ (La) to $28 \%(\mathrm{C})$ ), a maximum of the 3,4-content for $2^{\mathrm{Dy}} / \mathbf{A}$ and $\mathbf{2}^{\mathrm{Ho}} / \mathbf{B}$, as well as a constantly levelling 3,4-content at $<5 \%$ in case of cocatalyst $\mathbf{C}$ (Figure $2 \mathrm{a}-\mathrm{c}$ ). These findings might seem counterintuitive, as larger ions should provide more steric space for monomer coordination and the growing polymer chain and therefore favor cis-selectivity. As a clear identification of the active species was not successful so far, due to the paramagnetic character of most of the lanthanide ions and the low tendency of the active species toward crystallization, active species elucidation remains challenging. A reasonable interpretation of this polymerization behavior seems to be that solvent $[4,5,13,37]$, pre-reaction side products (e.g., $\mathrm{Ph}_{3} \mathrm{CMe} \mathrm{(A)} \mathrm{and} \mathrm{PhNMe}_{2}$ (B): $\mathrm{Ln}$ (III) — arene coordination) [38-40], or even anion coordination (e.g., via Ln(III) - F interactions) [41] come into play. Furthermore, dimerization might take place or a $\eta^{2}$-to- $\eta^{3}$ coordination switch of the remaining tetramethylaluminate moiety, which tendency seems more pronounced for the larger lanthanides as found for the neutral precatalysts $[4,10,12]$. Interestingly, the chain length/molecular weight averages of the obtained polymers were quite different throughout the series, revealing no clearly observable trend, although, a maximum in $M_{n}$ seems likely for $2^{\mathrm{Dy}} / \mathbf{A}$ and $2^{\mathrm{Ho}} / \mathrm{B}$ (Figure $3 \mathrm{a}-\mathrm{c}$ ). Maximum PDIs were obtained for the smallest $\mathrm{Ln}$ (III) centers. In case of cocatalyst $\mathbf{C}$, an increasing degree of polymerization and PDI was found with decreasing Ln ion size. 


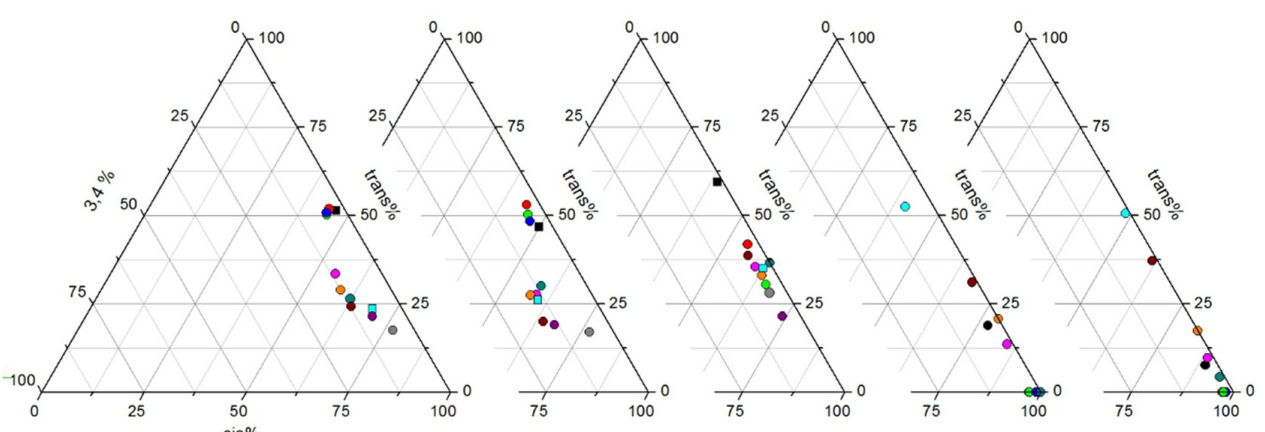

(a) (c) (d) (e)

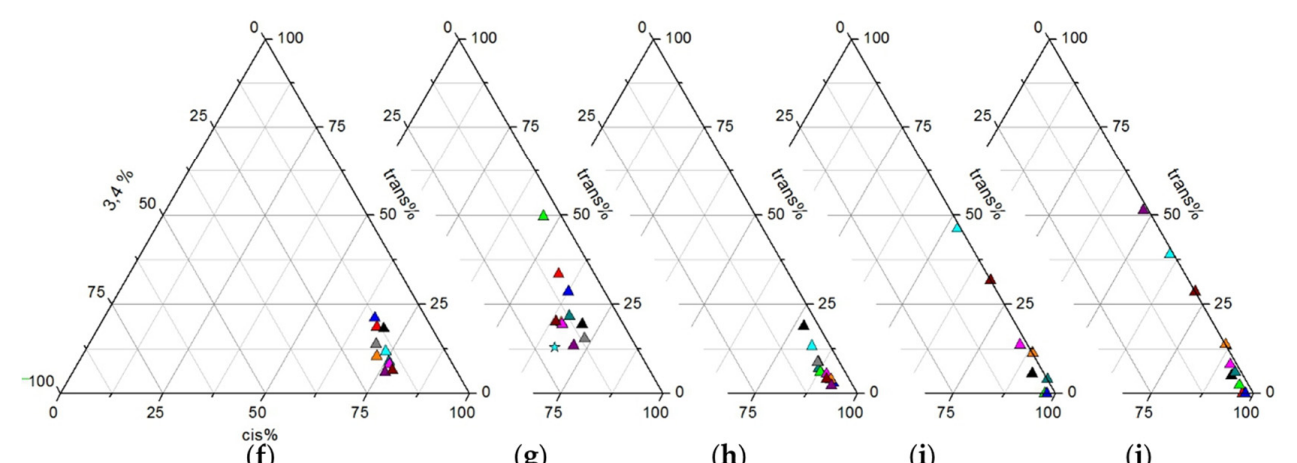

(g)

(i) (j)

Figure 2. Ternary diagrams representing the microstructure of the polyisoprenes obtained from $\mathrm{Ln}\left(\mathrm{AlMe}_{4}\right)_{3}\left(2^{\mathrm{Ln}}\right)$. Panels $(\mathbf{a}-\mathbf{j})$ give details on the selectivity obtained by the application of a certain cocatalyst (A-E (a-e) and 2 equiv. of $\mathbf{A}-\mathbf{E}(\mathbf{f}-\mathbf{j}) ; \mathbf{A}=\left[\mathrm{Ph}_{3} \mathrm{C}\right]\left[\mathrm{B}\left(\mathrm{C}_{6} \mathrm{~F}_{5}\right)_{4}\right], \mathbf{B}=\left[\mathrm{PhNMe}_{2} \mathrm{H}\right]\left[\mathrm{B}\left(\mathrm{C}_{6} \mathrm{~F}_{5}\right)_{4}\right]$, $\left.\mathbf{C}=\mathrm{B}\left(\mathrm{C}_{6} \mathrm{~F}_{5}\right)_{3}, \mathbf{D}=\mathrm{Me}_{2} \mathrm{AlCl}, \mathbf{E}=\mathrm{Et}_{2} \mathrm{AlCl}\right)$. Results for the addition of 1 equiv. of cocatalyst per $2^{\mathrm{Ln}}$ after $1 \mathrm{~h}$ are shown by circles, 2 equiv. by triangles. If such results were not available, microstructures of reaction times of $24 \mathrm{~h}$ are shown marked with squares and stars, respectively. Complexes $2^{\mathrm{Ln}}$ are color-coded regarding the Ln as follows: black (La), red (Ce), green (Pr), blue (Nd), teal (Gd), pink (Tb), orange (Dy), brown $(\mathrm{Ho})$, cyan $(\mathrm{Y})$, violet $(\mathrm{Er})$ and grey $(\mathrm{Lu})$. For a more traditional compilation of the polymer data in table form, sorted by precatalyst, see Tables S1.2.1—S1.2.11, Supplementary Materials. 


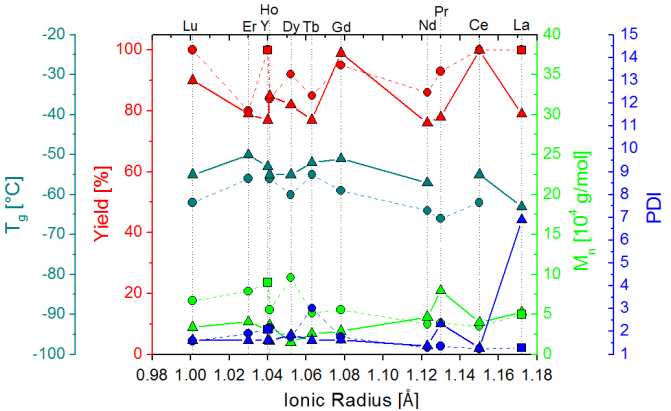

(a)

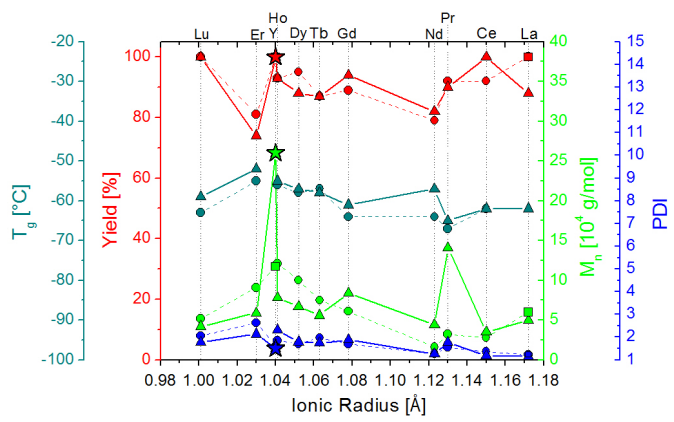

(b)

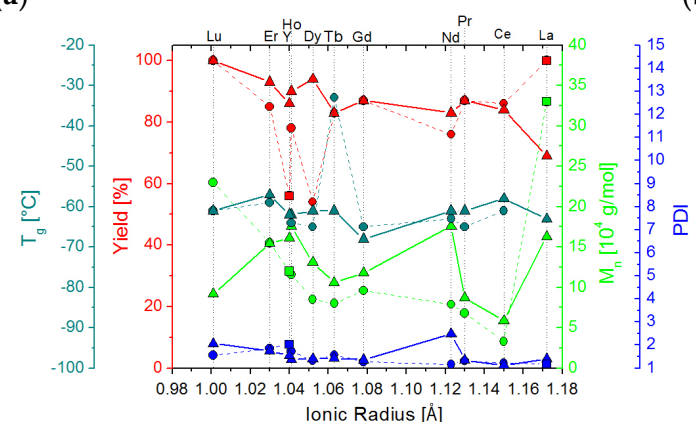

(c)

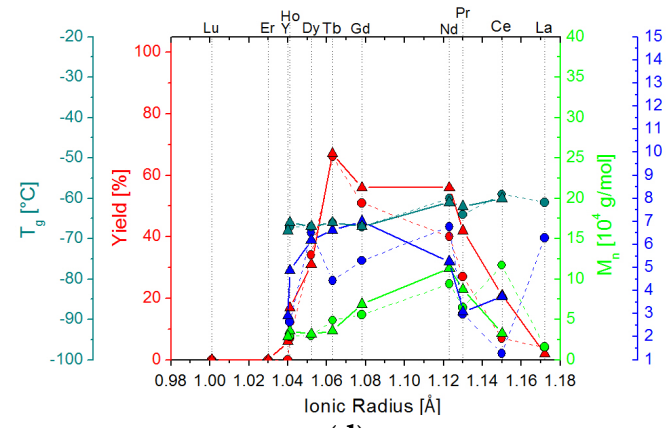

(d)

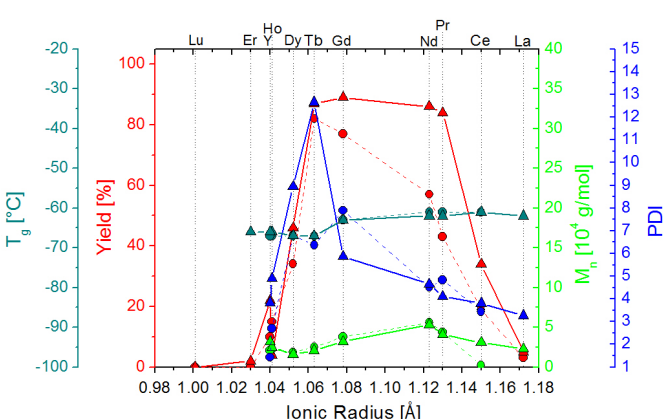

(e)

Figure 3. Overview charts representing the chain properties, yield and glass transition temperature of the polyisoprenes obtained from the homoleptic rare-earth metal tetramethylaluminates $2^{\mathbf{L n}}$. Panels (a-e) give details on the data obtained from the application of a certain cocatalyst (A-E; $\left.\mathbf{A}=\left[\mathrm{Ph}_{3} \mathrm{C}\right]\left[\mathrm{B}\left(\mathrm{C}_{6} \mathrm{~F}_{5}\right)_{4}\right], \mathbf{B}=\left[\mathrm{PhNMe}_{2} \mathrm{H}\right]\left[\mathrm{B}\left(\mathrm{C}_{6} \mathrm{~F}_{5}\right)_{4}\right], \mathbf{C}=\mathrm{B}\left(\mathrm{C}_{6} \mathrm{~F}_{5}\right)_{3}, \mathbf{D}=\mathrm{Me}_{2} \mathrm{AlCl}, \mathbf{E}=\mathrm{Et}_{2} \mathrm{AlCl}\right)$. Results for the addition of 1 equiv. of cocatalyst per aluminate precatalyst after $1 \mathrm{~h}$ are shown by circles (dashed lines), 2 equiv. by triangles (solid lines). If such results were not available, data of reaction times of $24 \mathrm{~h}$ are shown marked with squares and stars, respectively. The lanthanide precatalysts $\mathrm{Ln}\left(\mathrm{AlMe}_{4}\right)_{3}$ $\left(2^{\mathrm{Ln}}\right)$ are shown in the order of increasing ionic radii ( $x$-axis) [28,29]; the corresponding data are shown referring to four different y-axes: red (yield), green $\left(M_{\mathrm{n}}\right)$, blue (PDI) and teal $\left(T_{\mathrm{g}}\right)$. In all panels lines are meant to assist the reader to follow the certain curves within the plot and not to indicate linear behavior of the curves in between the points of measurement. For a more traditional compilation of the polymer data in table form, sorted by precatalyst, see Tables S1.2.1—S1.2.11, Supplementary Materials.

With respect to the uniformity of the polymerizing species ( $\mathrm{La}-\mathrm{Lu}$ ), the ratio of the number of polymer chains and the number of lanthanide centers showed maxima with the larger Ln for $\mathbf{A}$ and $\mathbf{B}$ (e.g., 3.37 for $2^{\mathrm{Nd}}$ ) and minima, where $M_{\mathrm{n}}$ is at its maximum ( $\mathrm{Ln}=\mathrm{Dy}(\mathbf{A})$ and $\left.\mathrm{Ln}=\mathrm{Ho}(\mathbf{B})\right)$, while it decreased for cocatalyst C (with exceptions for Ln = La and Lu, Table S3.1, Supplementary Materials). Therefore, the total number of active centers was lowest for $\mathrm{Ln}=\mathrm{Dy}(\mathbf{A})$ and $\mathrm{Ln}=\mathrm{Ho}(\mathbf{B})$ and decreased from $\mathrm{Ce}$ to $\mathrm{Er}$ for cocatalyst $\mathrm{C}$. This can be rationalized on the basis of coordination equilibria at least for the chain propagating species involving increasing coordination restrictions when moving from Ce to Er. For A and B then, substrate coordination capability is least pronounced, most likely caused by 
strong $\mathrm{Ln}^{3+}-\left[\mathrm{B}\left(\mathrm{C}_{6} \mathrm{~F}_{5}\right)_{4}\right]^{-}$interactions and competitive interactions with pre-reaction side products such as dimethylaniline. In total, these effects and peculiarities had only little influence on the glass transition temperatures, due to the vinylic content staying rather low in all cases. Besides these general trends in microstructure, several precatalyst/cocatalyst combinations stuck out. Here, especially for $2^{\mathrm{Gd}} / \mathbf{A}$, a much higher cis-content was found, than the trends discussed (vide infra) would imply.

Activation by a Single Equivalent of Dialkylaluminum Chloride. Unsurprisingly, the entirely different nature of cocatalysts $\mathrm{R}_{2} \mathrm{AlCl}(\mathrm{R}=\mathrm{Me}(\mathbf{D})$, Et (E)) and associated distinct activation pathways, led to a different set of results and interpretations (Figure 2d,e and Figure 3d,e, and Tables S1.1.4 and S1.1.5, Supplementary Materials). Most striking were the much higher cis-contents, achievable especially for the larger $\operatorname{Ln}\left(2^{\mathrm{Nd}} / \mathrm{D}, 98.9 \% ; \mathbf{2}^{\mathrm{Gd}} / \mathbf{D},>99.9 \%\right)$. The cis-content then dropped from $\mathrm{Ln}=\mathrm{Ho}$ on, giving way to an upcoming trans-content. As the transition state leading to trans-1,4-addition requires less space at the $\mathrm{Ln}(\mathrm{III})$ center than its cis-adding analogue, this result is in good agreement with the literature (for the evaluation of the microstructure data obtained, see Section 3.7) [42,43]. The obtained polymers showed constantly low contents of vinylic addition and therefore almost unaffected glass transition temperatures. Such binary catalyst systems $\mathbf{2}^{\mathrm{Ln}} / \mathbf{D}$ and $\mathbf{2}^{\mathrm{Ln}} / \mathbf{E}$ revealed a trend towards decreasing $M_{n}$ for smaller Ln with (almost) no yield at all for the smallest lutetium. Interestingly, the PDI and with it the (non)uniformity of the intended multimetallic active species, revealed a maximum for $\mathrm{Ln}=\mathrm{Dy}$. These data can be interpreted by the presence of an active species, that produces 'high-cis'-polyisoprene for the large rare-earth metals only. Due to coordination/space restraints at smaller lanthanide ions, cis-selectivity decreases on the expense of increasing trans-contents until monomer coordination is infeasible. The high cis-contents reached up to regions, where the other possible microstructures could not be observed anymore at all. While in the past, this had only been found for systems applying cocatalyst $\mathbf{E}$ in $n$-hexane [11], for $\mathrm{Ln}=\mathrm{Gd}$ such a high cis-content is also found in toluene (system $2^{\mathrm{Gd}} / \mathrm{D}$, Table S1.2.5, run 7, Supplementary Materials). Since the polydiene microstructure is routinely determined by combined ${ }^{1} \mathrm{H} /{ }^{13} \mathrm{C}$ NMR spectroscopies and the highest cis-contents have been routinely observed for the rare-earth elements neodymium and gadolinium, we would like to stress a degree of uncertainty related to selectivities larger than $98 \%$. Polymerization reactions are usually terminated by alcoholysis (=deactivation) of the catalyst system (see experimental part), resulting in inclusion of the quenching products into the polymer, which in case of, e.g., $\mathrm{Nd}(\mathrm{III})$ or $\mathrm{Gd}(\mathrm{III})$ is reflected in paramagnetic line broadening of the NMR spectra (Figure 4).

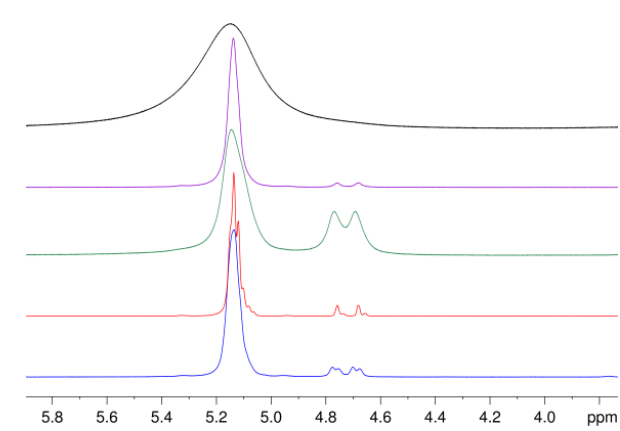

(a)

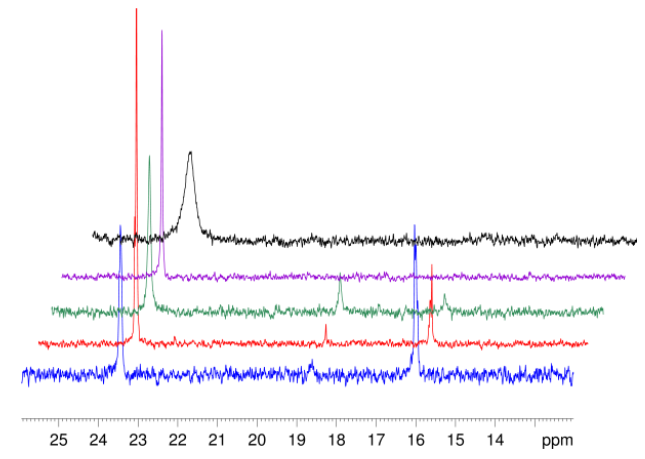

(b)

Figure 4. Comparison of ${ }^{1} \mathrm{H}$ NMR (a) and ${ }^{13} \mathrm{C}$ NMR spectra $(\mathbf{b})$ of selected polyisoprene samples (sorted by microstructure: decreasing trans-content bottom to top) produced by the systems $\mathrm{Nd}\left(\mathrm{AlMe}_{4}\right)_{3}$ $\left(2^{\mathrm{Nd}}\right) /\left[\mathrm{PhNMe}{ }_{2} \mathrm{H}\right]\left[\mathrm{B}\left(\mathrm{C}_{6} \mathrm{~F}_{5}\right)_{4}\right](\mathrm{B})$ (blue; cis/trans/vinylic $\left.=47 / 48 / 5 \%\right), \mathrm{La}\left(\mathrm{AlMe}_{4}\right)_{3}\left(2^{\mathrm{La}}\right) / 2 \mathrm{~B}\left(\mathrm{C}_{6} \mathrm{~F}_{5}\right)_{3}$ (C) (red; 78/19/4\%), Dy $\left(\mathrm{AlMe}_{4}\right)_{3}\left(2^{\mathrm{Dy}}\right) / 2\left[\mathrm{Ph}_{3} \mathrm{C}\right]\left[\mathrm{B}\left(\mathrm{C}_{6} \mathrm{~F}_{5}\right)_{4}\right]$ (A) (green; 72/10/18\%), $\mathrm{Nd}\left(\mathrm{AlMe}_{4}\right)_{3}$ $\left(2^{\mathrm{Nd}}\right) / \mathrm{Me}_{2} \mathrm{AlCl}(\mathrm{D})$ (violet, $99 / 0 / 1 \%$ ) and $\mathrm{Gd}\left(\mathrm{AlMe}_{4}\right)_{3}\left(2^{\mathrm{Gd}}\right) / \mathrm{Me}_{2} \mathrm{AlCl}$ (D) (black; >99/0/0\%). Inclusion of the quenching products into the polymer cannot be fully avoided. In case of polymers produced by paramagnetic catalyst systems this causes a broadening of the signals that increases the error of microstructure determination. 
Moreover, the suitability of ATR-IR spectroscopy was probed as a pre-screening method for examining the microstructure of the polyisoprenes. For several polymer samples, both NMR and ATR-IR spectroscopic data have been compiled, in order to determine any significant deviation (Figure 5; Figures S2.1.1-S2.4.1 and Tables S2.1.1-S2.4.1, Supplementary Materials). Most satisfyingly, both methods are in good agreement taking into account the errors of the measurements.

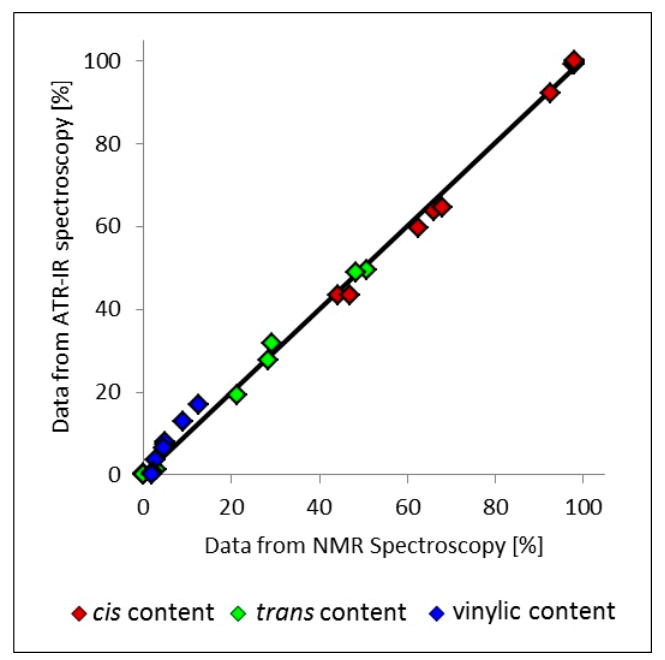

Figure 5. (See also Figure S2.2.1, Supplementary Materials). Comparison of the microstructure results obtained by NMR and ATR-IR spectroscopy, applying $\mathrm{Nd}\left(\mathrm{AlMe}_{4}\right)_{3}\left(2^{\mathrm{Nd}}\right)$ and cocatalysts A-E $\left(\mathbf{A}=\left[\mathrm{Ph}_{3} \mathrm{C}\right]\left[\mathrm{B}\left(\mathrm{C}_{6} \mathrm{~F}_{5}\right)_{4}\right], \mathbf{B}=\left[\mathrm{PhNMe}_{2} \mathrm{H}\right]\left[\mathrm{B}\left(\mathrm{C}_{6} \mathrm{~F}_{5}\right)_{4}\right], \mathbf{C}=\mathrm{B}\left(\mathrm{C}_{6} \mathrm{~F}_{5}\right)_{3}, \mathbf{D}=\mathrm{Me}_{2} \mathrm{AlCl}, \mathbf{E}=\mathrm{Et}_{2} \mathrm{AlCl}\right)$ in both 1 and 2 equiv. For detailed polymerization data see Tables S1.2.4 and S2.2.1 (Supplementary Materials).

Activation by Two Equivalents of Borate/Borane. Addition of a second equiv. of the respective cocatalyst theoretically produces two cationic charges per lanthanide metal center and is therefore assumed to change the polymerization capabilities of the active sites significantly [44,45]. Surprisingly, for cocatalysts $\mathbf{A}$ or $\mathbf{B}$ and with the exception of $\mathrm{Ln}=\mathrm{La}$, the polydispersities were found in the same range as in case of single cationization, although some polyisoprenes revealed smaller values as anticipated (Figure 3a,b, Tables S1.1.1 and S1.1.2, Supplementary Materials). Taking into account similar polymer yields, this implies that the uniformity of the active center is not much affected. In contrast, the number average molecular weights differed markedly. Although there was still no clear trend observable across the series La-Lu, polymerization initiation was visibly influenced by the second equiv. of cocatalyst as the $\mathrm{n}$ (chains) / $\mathrm{n}$ (Ln centers) ratios have changed to a large extent (Table S3.1, Supplementary Materials). Interestingly, throughout the whole Ln series, the cis-contents were found in the same area as observed for the catalysts derived from smaller Ln using 1 equiv. of cocatalyst. Twofold cationization is proposed to displace another tetramethylaluminate moiety, thus increasing steric unsaturation (and electron deficiency) at the rare-earth metal center. This can explain the comparatively higher cis-selectivities for the larger Ln, but cannot account for the concomitantly observed increased 3,4-contents (also affecting the glass transition temperatures). A preferred coordination of solvent or pre-reaction side products at such highly electron-deficient $\operatorname{Ln}$ (III) centers seems a plausible explanation for the latter [13,46]. When 2 equiv. of A were applied on the largest $\mathrm{Ln}(\mathrm{III}), \mathrm{Ln}=\mathrm{La}$ and $\operatorname{Pr}$ (where Ce is an exception due to its potential to undergo redox behavior) a radical side reaction was observed that caused crosslinking of the resulting polymers and swelling on the application of solvents.

For 2 equiv. of cocatalyst $\mathbf{C}$, even higher cis-contents than in case of $\mathbf{A}$ and $\mathbf{B}$ could be realized (Figure 2h, Table S1.1.3, Supplementary Materials). As with this neutral borane no pre-reaction side products are formed, competition for coordination sites with the monomer seems less pronounced, which might also explain the relatively low PDI. In contrast to the polymers formed with only 1 equiv. 
of cocatalyst $\mathbf{C}$, there is no clear trend visible for the chain length. Instead, several more or less favored combinations of ion size with its environment and monomer are suggested.

Activation by Two Equivalents of Dialkylaluminum Chloride. Addition of 2 equiv. of the cocatalysts $\mathrm{R}_{2} \mathrm{AlCl}$ (see Section 2.2.2, for a more detailed study on the influence of the cocatalyst concentration) resulted in even more complicated systems in terms of PDI values than observed for 1:1 binary mixtures. Still, extremely high cis-contents and acceptable yields could be achieved for the larger $\mathrm{Ln}$, down to $\mathrm{Tb}$, where yields and cis-contents once again dropped and trans-1,4-addition became significant. Here, neodymium displayed the highest cis-contents with both cocatalysts $\mathbf{D}$ and E (maximum 98\%). The application of $\mathrm{R}_{2} \mathrm{AlCl}$ is limited though, as it only provides reasonable yields with the medium-sized lanthanides.

Overall Maxima. Overviewing all results (Tables S1.3.1-S1.3.7, Supplementary Materials) revealed that there are high-yielding precatalyst/cocatalyst combinations for each lanthanide and cocatalyst (cf. Figure 2). The highest cis-contents were found for cocatalysts $\mathrm{R}_{2} \mathrm{AlCl}$ (D and E), especially with $\mathrm{Ln}=\mathrm{Ce}, \mathrm{Pr}, \mathrm{Nd}, \mathrm{Gd}$, showing virtually complete cis-selectivity, while the highest induced by the borate/borane cocatalysts was found for $2^{\mathrm{Nd}} / 2 \mathrm{C}(92.7 \%)$. The most trans-selective combinations accomplished medium selectivity $(<60 \%)$ for $\mathrm{Ln}=\mathrm{La}$ and the borate/borane cocatalysts (A-C) [18]. The vinylic contents did not succeed $20 \%\left(2^{\mathrm{Y}} / 2 \mathbf{B}\right)$ [16]. Interestingly, the uniformity of the active systems was highest for $\mathrm{Ln}=\mathrm{Ce}$ showing even a PDI $<1.2$ with 2 equiv. of $\mathbf{B}$ and a surprisingly low PDI ( $<1.3)$ with 1 equiv. of $\mathbf{D}$ as well (Table S1.2.2, Supplementary Materials), in comparison with the generally high PDIs for $\mathrm{R}_{2} \mathrm{AlCl}$-cocatalyzed polymerizations.

\subsubsection{Screening Studies}

Screening of the Pre-Reaction Time. The pre-reaction time of $0.5 \mathrm{~h}$ has originally been chosen to ensure complete catalyst formation before monomer addition. Due to the paramagnetic character of most of the lanthanides, an exact determination of the active species by NMR spectroscopy during the process of formation remains challenging. For the few diamagnetic systems, the small total number of signals and the high mobility of the $\left[\mathrm{AlMe}_{4}\right]^{-}$moieties further hampered a detailed elucidation $[4,10,12]$. Therefore, the active species was investigated indirectly by empirically screening various pre-reaction times applying $\mathrm{Nd}\left(\mathrm{AlMe}_{4}\right)_{3}\left(2^{\mathrm{Nd}}\right)$ and cocatalyst $\mathbf{E}$, which, in this study, served as a representative example for the $\mathrm{R}_{2} \mathrm{AlCl}$ cocatalyst systems. It was revealed that the microstructure remained surprisingly constant (cis/trans/vinylic $=98 / 0 / 2 \%$, Figure S1.4.1 and Table S1.4.1, Supplementary Materials). Interestingly, polymer yields were higher for shorter pre-reaction times than for the standardized $30 \mathrm{~min}$, if a minimum of $10 \mathrm{~min}$ was allowed. At the same time, the number average molecular weight remained rather constant, which implies a higher number of initiating $\mathrm{Nd}$ centers under these conditions (Figure 6a). At $22 \mathrm{~min}$ of pre-reaction time almost every Nd center (extrapolated) produced a polymer chain (for details on the calculation of ratios $\mathrm{n}$ (chains) $/ \mathrm{n}$ (Ln centers), see Section S3 in the Supplementary Materials). In addition, the ratio $n$ (chains) $/ \mathrm{n}$ (Ln centers) decreased below $80 \%$ at the originally applied $0.5 \mathrm{~h}$. Considering the occurrence of multimetallic active species (cluster), the elucidation of the nature of such seemingly high initiation rates remain subject to future research. 


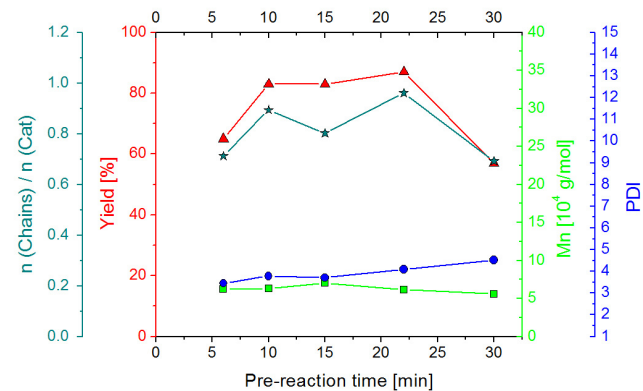

(a)

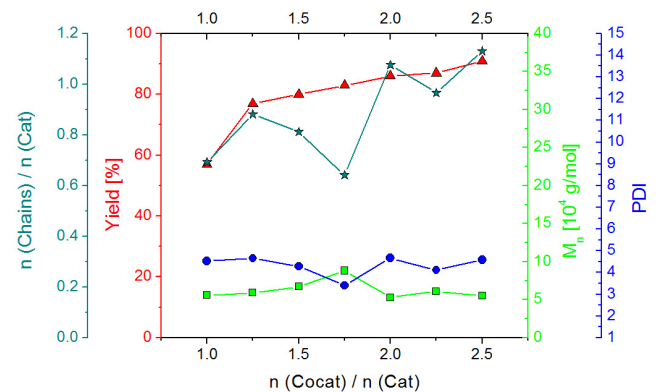

(b)

Figure 6. Overview on isoprene polymerization data obtained, when investigating the influence of pre-reaction time (panel a) and cocatalyst concentration (b), applying the catalytic system $\mathrm{Nd}\left(\mathrm{AlMe}_{4}\right)_{3}$ $\left(2^{\mathrm{Nd}}\right) / \mathrm{Et}_{2} \mathrm{AlCl}(\mathrm{E})$ with a pre-reaction time of $30 \mathrm{~min}$ as an example. The corresponding data are shown referring to four different $y$-axes: red (yield), green $\left(M_{n}\right)$, blue (PDI) and teal (extrapolated ratio $\mathrm{n}$ (polymer chains)/n(Nd centers)). For details on the calculation of ratios $\mathrm{n}$ (chains)/n(Ln centers), see Section S3 of the Supplementary Materials. During these screenings, the microstructure remained constantly around cis/trans $/ 3,4=98 / 0 / 2 \%$ (see Figure S1.4.1, Supplementary Materials). In both panels, lines are meant to assist the reader to follow the respective curves within the plot and not to indicate linear behavior of the curves in between the points of measurement.

We hypothesize that monomer coordination breaks up the multimetallic entities (compare Section 2.3.2). This theory would not interfere with the PDI values, which increase with longer pre-reaction times as a result of the formation of a variety of cationic multimetallic species. More precisely, initially formed larger units might dissociate into chain propagating species in multiple steps, releasing propagating systems stepwise and therefore subsequently. Table S3.1 (Supplementary Materials) gives an overview on the ratio $\mathrm{n}$ (chains) $/ \mathrm{n}$ (Ln centers) found in this study at standard conditions ( 1 and 2 equiv. of cocatalyst and $0.5 \mathrm{~h}$ pre-reaction time, screening of precatalysts $2^{\text {Ln }}$ and cocatalysts A-E). Apparently, values above 1, implying chain transfer at monocationic species, are more often obtained with cocatalysts $\mathbf{A}-\mathbf{C}$, while low values $(<<1)$ accumulated with cocatalysts $\mathbf{D}$ and $\mathbf{E}$. Therefore, we assume that disaggregation did not occur to full extent for all precatalysts, as the steric situations created by those vary due to the different ion sizes.

Screening of the Cocatalyst Concentration. Since multimetallic cationic species have been proposed to form upon cocatalyst addition [11], gradual variation of the cocatalyst concentration should provide further insight into the active species (Figure 6b, Table S1.4.2, Supplementary Materials). Accordingly, increasing amounts of cocatalyst resulted in an overall increase in yield and the extrapolated molar ratio of polymer chains per $\mathrm{Nd}$ center, while the microstructures and chain lengths remained once more rather unaffected. The ratio $\mathrm{n}$ (chains) $/ \mathrm{n}$ (Ln centers) even reached beyond 1, implying minimal amounts of chain transfer. This can be explained by free $\mathrm{AlMe}_{3}$, which has a low capability of serving as a chain transfer agent [47]. This would also cause the occurrence of dormant species as described by Brintzinger et al. [48]. As the capability of $\mathrm{AlR}_{3}$ species to serve as a chain transfer agent increases with the length of $\mathrm{R}$ that of ' $\mathrm{Et}_{2} \mathrm{AlMe}$ ' (formed in the pre-reaction applying cocatalyst E) should be higher than that of $\mathrm{AlMe}_{3}[49,50]$. The slightly increasing yield with increasing cocatalyst concentration implies a slightly increasing number of catalytically active centers, in view of the almost constant molecular weight. Interpretations ascribing these findings to chain transfer behavior alone seem rather unlikely, as it would then be implausible to obtain constant number average molecular weights. Still, chain transfer plays undoubtedly a (small) role with these systems (vide supra). As well, it seems unlikely, that these results could be caused by a multimetallic species containing several active centers. In such a sterically crowded event, it would occur counterintuitive, that the same active species provides higher ratios $\mathrm{n}$ (chains) $/ \mathrm{n}(\mathrm{Nd}$ centers) for isoprene than for the sterically less demanding 1,3-butadiene (vide infra). 
Isoprene Polymerization in $n$-Hexane. Polymerizations in $n$-hexane, applying $2^{\mathrm{Nd}} / \mathbf{E}$ (Table S1.4.3., Supplementary Materials) showed that while microstructure, molecular weight and yield are only affected slightly, the impact on the polydispersity is significant at ambient temperature. Such high PDI values can be explained by the re-dissolution of the precipitated multimetallic catalyst species upon monomer addition, which is slower in $n$-hexane than toluene $[4,11,13]$. The availability of the active species should be limited in a system, where the precipitate is less soluble. Increasing the solubility by application of higher temperatures (e.g., $40^{\circ} \mathrm{C}$ ) resulted in quantitative yields after $24 \mathrm{~h}$ and a lower PDI than in toluene [13]. Addition of only a small amount of toluene (Table S1.4.3, run 2) afforded the microstructure and chain length obtained in pure toluene. Interestingly, the latter system seemed to yield more lanthanide centers growing a polymer chain, which resulted in a lower PDI and higher yield.

Longer Reaction Times with Less-Active Catalysts. Precatalyst/cocatalyst combinations that have only resulted in traces of polymer after a reaction time of $1 \mathrm{~h}$, were probed in $24 \mathrm{~h}$ terms as well (Table S1.4.4, Supplementary Materials). The binary system $2^{\mathrm{La}} / \mathrm{D}$ resulted in microstructure and chain properties in the anticipated range but uniquely in this study, 1,2-addition was found for one polyisoprene sample $(0.8 \%)$. Furthermore, the notably high trans-contents observed for the smaller Ln $(\mathrm{Er}, \mathrm{Lu})$ are to mention, following the trends described in Section 2.2 .1 to the maximal extent of $81 \%$ of 1,4-trans linkages $\left(2^{\mathrm{Lu}} / 2 \mathrm{E}\right)$.

\subsection{1,3-Butadiene Polymerization Catalysis}

\subsubsection{Polymers Obtained at Standard Conditions}

The polymerization of 1,3-butadiene was investigated for praseodymium, neodymium and yttrium. Overall, a similar set of results was obtained as in case of isoprene polymerization although vinylic addition was even less pronounced (Figure 7a and Tables S1.6.1-S1.6.3). While the microstructure of polybutadienes obtained with $2^{\mathrm{Pr}}$ activated by borate/borane cocatalysts $(\mathrm{A}-\mathrm{C})$ showed predominant trans-1,4 selectivity, the high cis-1,4 selectivities in the presence of cocatalysts $\mathrm{R}_{2} \mathrm{AlCl}$ ( $\mathbf{D}$ and $\mathbf{E}$ ) were detected for 1,3-butadiene as well. As in the isoprene case, the smaller-sized D produced the highest cis-selectivities, accomplishing $99.7 \%$ for $\mathrm{Ln}=\mathrm{Nd}$ (Figure 7a, Table S1.6.2, Supplementary Materials). In all cases the yields remained rather low, probably due to shear-induced gelation of the solutions of growing polymer chains and low initiation rates. These are also the reasons for the rather high molecular weights and the variations in PDI (see Figure $7 \mathrm{~b}$ and Tables S1.6.1-S1.6.3). For geometric reasons, 3000 equiv. of monomer per Ln center were not reached in all experiments (the actual amounts were determined by flowmeter and are given in the respective tables in Sections S1.6 and S1.7, Supplementary Materials).

\subsubsection{Screening Studies}

Both panels of Figure 8 show that the catalytic situation is more complicated when applying 1,3-butadiene, instead of isoprene (compare Section 2.2.2). Once again, neodymium tetramethylaluminate $2^{\mathrm{Nd}}$ was chosen as an exemplary precatalyst. The number of polymer chains produced per Nd center is significantly lower than in the isoprene case, especially at pre-reaction times longer than $15 \mathrm{~min}$. This initiation deficit implies that the suggested disaggregation of the multimetallic cationic species is less pronounced (if it happens at all in the 1,3-butadiene case). 


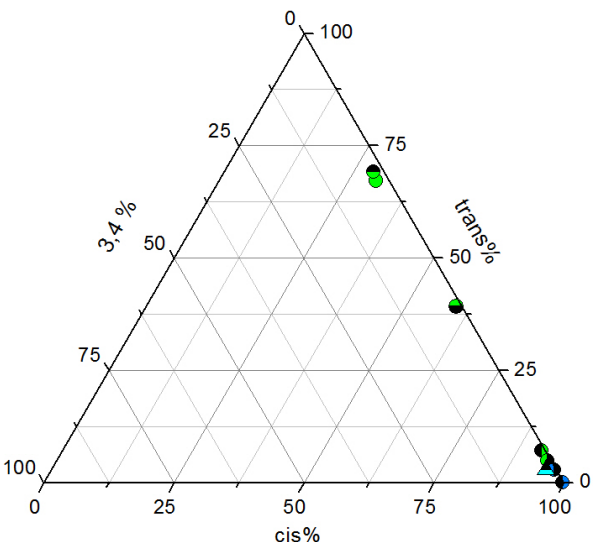

(a)

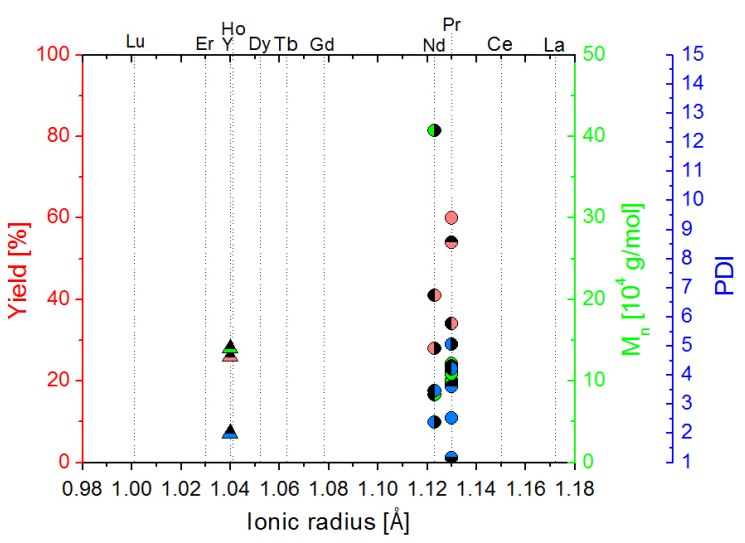

(b)

Figure 7. Overview on 1,3-butadiene polymerization data. In both panels, the black parts of the marks represent the cocatalyst applied: none: $\mathbf{A}$, top: $\mathbf{B}$, bottom: $\mathbf{C}$, right: $\mathbf{D}$ and left $\mathbf{E}\left(\mathbf{A}=\left[\mathrm{Ph}_{3} \mathrm{C}\right]\left[\mathrm{B}\left(\mathrm{C}_{6} \mathrm{~F}_{5}\right)_{4}\right]\right.$, $\left.\mathbf{B}=\left[\mathrm{PhNMe}_{2} \mathrm{H}\right]\left[\mathrm{B}\left(\mathrm{C}_{6} \mathrm{~F}_{5}\right)_{4}\right], \mathbf{C}=\mathrm{B}\left(\mathrm{C}_{6} \mathrm{~F}_{5}\right)_{3}, \mathbf{D}=\mathrm{Me}_{2} \mathrm{AlCl}, \mathbf{E}=\mathrm{Et}_{2} \mathrm{AlCl}\right)$. Results for the addition of 1 equiv. of cocatalyst per aluminate precatalyst are shown by circles, 2 equiv. by triangles. (a) ternary diagram representing the microstructure of the polybutadienes obtained from homoleptic lanthanide tetramethylaluminates. Precatalysts $2^{\mathrm{Ln}}(\mathrm{Ln}=\mathrm{Pr}, \mathrm{Nd}, \mathrm{Y})$ are color-coded as follows: green $(\mathrm{Pr})$, blue $(\mathrm{Nd})$, cyan $(\mathrm{Y})$. (b) overview chart representing the chain properties and yield of the polybutadienes. Rare-earth metal precatalysts $2^{\mathrm{Ln}}$ are shown in the order of increasing ionic radius ( $x$-axis); the corresponding data are shown referring to three different $y$-axes: red (yield), green $\left(M_{n}\right)$, blue (PDI).

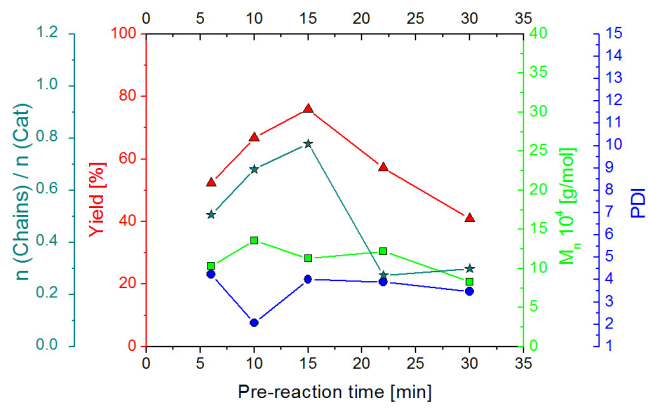

(a)

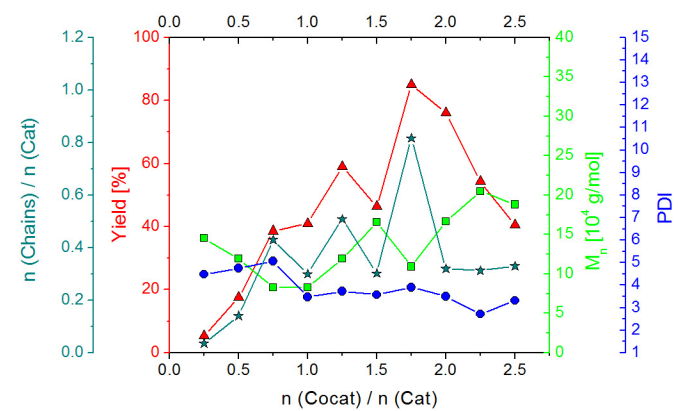

(b)

Figure 8. Overview on 1,3-butadiene polymerization data obtained, when investigating the influence of pre-reaction time panel (a) and cocatalyst concentration (b), applying the catalytic system $\mathrm{Nd}\left(\mathrm{AlMe}_{4}\right)_{3}\left(2^{\mathrm{Nd}}\right) / \mathrm{Et}_{2} \mathrm{AlCl}(\mathrm{E})$ with a pre-reaction time of $30 \mathrm{~min}$ as an example. The corresponding data are shown referring to four different $y$-axes: red (yield), green $\left(M_{n}\right)$, blue (PDI) and teal (extrapolated ratio $\mathrm{n}$ (polymer chains) $/ \mathrm{n}(\mathrm{Nd}$ centers)). For details on the calculation of ratios $\mathrm{n}$ (chains)/n(Ln centers), see Section S3 of the Supplementary Materials. During these screenings, the polybutadiene microstructure showed a small increase $96.7-98.8 \%$ with shorter pre-reaction times and remained constant with higher cocatalyst concentrations until 2.5 equiv. were reached, where it increased to cis $/$ trans $/$ vinylic $=99.5 / 0.4 / 0.1 \%$ (Figure S1.7.1 and Tables S1.7.1 and S1.7.2, Supplementary Materials). In both panels lines are meant to assist the reader to follow the certain curves within the plot and not to indicate linear behavior of the curves in between the points of measurement.

Screening of the Pre-Reaction Time. Variation of the pre-reaction time resulted in maximum monomer conversion after $15 \mathrm{~min}$, while $M_{\mathrm{n}}$ remained rather constant. The latter can be explained by an increased number of active centers (or enhanced chain transfer, which once more seems unlikely, see Section 2.2.2). With an enduring activation reaction, such an increase would not be 
too surprising, but interestingly, after $15 \mathrm{~min}$, the number of active centers seem to decrease as indicated by a significant drop of the ratio of chains per Ln center. Assuming the growth of one polymer chain per Ln(III) center, about two of three Ln centers seem not to grow a polymer chain. The following two scenarios seem likely: either it is indeed higher aggregates that propagate polymer chains or a disaggregation/re-aggregation occurs, which causes chain termination at a very early state and terminates the catalytic capabilities of certain Ln centers. While the approximate 1:2 molar ratio of polymer chains per Ln center favors the first option, the fact that PDI, degree of polymerization and even the microstructure was not affected might speak in favor of the second scenario. The highest cis-contents were observed at the shortest pre-reaction time ( $98.8 \%$ after $6 \mathrm{~min})$, staying at a very high level of $96.7 \%$ even after a pre-reaction time of $30 \mathrm{~min}$.

Screening of the Cocatalyst Concentration. As 30 min was the originally chosen pre-reaction time, it was also applied in the cocatalyst concentration screening (Figure 8b, Table S1.7.2, see Supplementary Materials). Not unexpectedly, using 0.25 equiv. of cocatalyst per $\mathrm{Nd}$ center gave low polymer yield, featuring long polymer chains as only a small number of active $\mathrm{Nd}$ centers propagated chain growth. Up to 0.75 equiv. of cocatalyst, the curves followed the expected paths, revealing increasing yield, decreasing molecular weight, since involving a higher number of active $\mathrm{Nd}$ centers. Noteworthy, a comparatively high PDI was observed for a ratio $\mathbf{E} / \mathbf{2}^{\mathbf{N d}}<1$. The polymerization performance appeared completely altered at higher cocatalyst concentrations. The number of active centers as well as the PDI dropped at 1 equiv. of cocatalyst. Hence, less but more uniform active centers were produced. Furthermore, the new species seemed less active as monomer uptake, that had remained constant so far, dropped as well $(34.1 \rightarrow 22.4 \mathrm{mmol}$ ), at rather constant yield (Table S1.7.2, Supplementary Materials). Despite of two exceptional catalyst/cocatalyst ratios (1.25 and 1.75), the active species present with 1 equiv. of cocatalyst seemed to stay intact up to the highest tested ratio of 2.5, as PDI and ratio $\mathrm{n}$ (chains) $/ \mathrm{n}$ (Ln center) remained rather constant. As expected, cocatalyst concentrations larger than 2 equiv. resulted in lower yields due to loss of active $\mathrm{Nd}$-alkyl moieties (=catalyst poisoning) [11]. Interestingly, the molar ratio of chains per $\mathrm{Nd}$ center seemed not affected. It is not yet clear why the catalyst species generated by 1.25 and 1.75 equiv. of cocatalyst $E$ afforded a seemingly increased number of active centers and higher yield at rather unaffected polymer chain properties $\left(M_{n}\right.$, PDI).

Further Studies on 1,3-Butadiene Polymerization. As a prove of principle, a 1,3-butadiene polymerization with $2^{\mathrm{Nd}} / \mathrm{E}$ was run for $2 \mathrm{~h}$ (Table S1.7.3, Supplementary Materials). Increased yield, $M_{\mathrm{n}}$ as well as monomer uptake suggested that the reaction continues with a slight loss of polymerization rate, due to enhanced viscosity.

1,3-Butadiene polymerization with $2^{\mathrm{Nd}} / \mathbf{E}$ in $n$-hexane (Table S1.7.4, Supplementary Materials) differed markedly from the same experiment performed with isoprene (Section 2.2.2). The polydispersity of the polybutadienes seemed unaffected by the solvent change. However, the number average molecular weights were much higher in $n$-hexane than in toluene at rather constant yield, suggesting that less Nd centers grow a polymer chain. The increased monomer uptake of the solution is ascribed to the different solubility of 1,3-butadiene in the applied solvents. Still, the availability of the monomer is therefore high, which causes the high $M_{n}$ produced by the fewer active sites.

\subsection{Ethylene Polymerization}

Preliminary ethylene polymerizations have been performed with $\mathbf{2}^{\mathrm{Nd}} / \mathbf{E}$ and $\mathbf{2}^{\mathrm{Nd}} / \mathbf{2 E}$ (Table S1.8.1, Supplementary Materials), affording $12 \%$ and $87 \%$ yield of polyethylene, respectively, with similar average molecular weights. The higher PDI of 4.0 in case of 2 equiv. of cocatalyst (compared to 3.4 with 1 equiv.) is reflected in the melting points of the two samples which differ by $8 \mathrm{~K}\left(\mathrm{E}: 138^{\circ} \mathrm{C}\right.$, 2E: $130^{\circ} \mathrm{C}$ ). An extension of this study is subject to further research. 


\section{Materials and Methods}

\subsection{General Remarks}

All operations were performed with rigorous exclusion of air and water, using standard Schlenk, high-vacuum and argon glovebox techniques (MBraun MB 200B; <1 ppm $\mathrm{O}_{2},<1$ ppm $\mathrm{H}_{2} \mathrm{O}$ ). When autoclaves did not fit into the antechambers of the applied gloveboxes (Parr type, used for ethylene polymerization), air and moisture were excluded from autoclaves as well by evacuation at reaction temperature for $24 \mathrm{~h}$ prior to the polymerizations and insertion of educts applying shuttles filled in a glovebox. Otherwise (Büchi type, used for 1,3-butadiene polymerization) the applied miniclaves were filled and sealed inside a glovebox. $n$-Hexane, toluene and THF (Sigma-Aldrich, St. Louis, MO, USA) were purified by using Grubbs columns (MBraun SPS-800, solvent purification system, Garching, Germany) and stored in a glovebox. $\mathrm{C}_{6} \mathrm{D}_{6}$ and toluene- $\mathrm{d}_{8}$ were obtained from Sigma-Aldrich, dried over $\mathrm{NaK}$ alloy for $24 \mathrm{~h}$ and filtered. Anhydrous $\mathrm{LnCl}_{3}$ were purchased from ABRC chemicals (Karlsruhe, Germany) and were activated by Soxhlet extraction with THF. $\mathrm{CDCl}_{3}$ and $\mathrm{AlMe}_{3}$ were purchased from Sigma-Aldrich and used as received. Trioctylaluminum and methyllithium were obtained from Sigma-Aldrich as solutions in hexanes and were used after solvent evaporation. $\mathrm{LiNMe}_{2}$ was synthesized from $\mathrm{HNMe}_{2}$ and $n$-BuLi (both Sigma-Aldrich) and employed as white powder. Isoprene was obtained from Sigma-Aldrich, dried over trioctylaluminum and vacuum transferred prior to use. $\left[\mathrm{Ph}_{3} \mathrm{C}\right]\left[\mathrm{B}\left(\mathrm{C}_{6} \mathrm{~F}_{5}\right)_{4}\right](\mathrm{A})$, $\left[\mathrm{PhNMe}{ }_{2} \mathrm{H}\right]\left[\mathrm{B}\left(\mathrm{C}_{6} \mathrm{~F}_{5}\right)_{4}\right](\mathbf{B})$ and $\mathrm{B}_{(}\left(\mathrm{C}_{6} \mathrm{~F}_{5}\right)_{3}$ (C) were purchased from Boulder Scientific Company (Longmont, CO, USA) and used without any further purification. 1,3-Butadiene and ethylene, as well as nitrogen and helium (atmosphere gasses for DSC), were purchased from Westphalen Gas (Münster, Germany) and purified and dried over Grubbs columns prior to use. Their amounts were determined using a Bronkhorst EL Flow Select Flow Controller (Ruurlo, The Netherlands). Homoleptic methylaluminate complexes $2^{\mathrm{Ln}}$ were prepared according to literature methods [4,11-13,20-23]. The NMR spectra of air- and moisture-sensitive compounds were recorded at $25{ }^{\circ} \mathrm{C}$ on a Bruker DMX-400 Avance $\left({ }^{1} \mathrm{H}: 400.13 \mathrm{MHz} ;{ }^{13} \mathrm{C}: 100.61 \mathrm{MHz}\right.$; ${ }^{27} \mathrm{Al}: 130.33 \mathrm{MHz}$ ) (Billerica, MA, USA). ${ }^{1} \mathrm{H},{ }^{13} \mathrm{C}$ and ${ }^{27} \mathrm{Al}$ shifts are referenced to internal solvent resonances and reported in parts per million ( $\mathrm{ppm}$ ) relative to TMS. Elemental analyses were performed on an Elementar Vario MICRO cube (Hanau, Germany). The molar weights $\left(M_{\mathrm{W}}\right.$ and $M_{\mathrm{n}}$ ) of the polymers were determined by size-exclusion chromatography (SEC). Sample solutions (1.0 $\mathrm{mg}$ polymer per mL THF) were filtered through a $0.45 \mu \mathrm{m}$ syringe filter (Macherey-Nagel, Düren, Germany) prior to injection. SEC was performed with a pump supplied by Viscotek (GPCmax VE 2001, Malvern, UK), employing ViscoGEL columns. Signals were detected by means of a triple detection array (TDA 305) and calibrated against polystyrene standards $\left(M_{\mathrm{W}} / M_{\mathrm{n}}<1.15\right.$; Malvern, UK, and PSS Polymer Standards Service GmbH, Mainz, Germany). The flowrate was set to $1.0 \mathrm{~mL} \mathrm{~min}^{-1}$. High temperature GPC was performed by Malvern Instruments Ltd. The microstructures of the polydienes were examined by means of ${ }^{1} \mathrm{H}$ and ${ }^{13} \mathrm{C}$ NMR spectroscopic experiments on the AV400 spectrometer at ambient temperature, using $\mathrm{CDCl}_{3}$ as a solvent and by ATR-IR spectroscopy on a Thermo Fisher Scientific NICOLET 6700 FTIR spectrometer using a diamond ATR setup (Waltham, MA, USA). Glass transition temperatures of the polymers $\left(T_{\mathrm{g}}\right)$ were obtained applying a Perkin-Elmer DSC 8000 calibrated with indium and cyclohexane standards, scanning from $-100{ }^{\circ} \mathrm{C}$ up to $+100{ }^{\circ} \mathrm{C}$ with heating rates of $20 \mathrm{~K} / \mathrm{min}$ and cooling rates of $60 \mathrm{~K} / \mathrm{min}$ in $\mathrm{N}_{2}$ atmosphere (polyisoprene) and He atmosphere (polybutadiene). Crystals of $2^{\mathrm{Gd}}$ and $\mathbf{2}^{\mathrm{Tb}}$ suitable for X-ray crystallography were grown by standard techniques from solutions using $n$-hexane at $-35^{\circ} \mathrm{C}$. Single crystals were selected, coated with Parabar 10312 (previously known as Paratone N, Hampton Research, Aliso Viejo, CA, USA) and fixed on a microloop. Data were collected on a Bruker APEX DUO instrument (Billerica, MA, USA) equipped with an I $\mu$ S microfocus sealed tube and QUAZAR optics for MoK $\alpha$ radiation $(\lambda=0.71073 \AA)$. The data collection strategy was determined using COSMO (Version 1.61, Bruker AXS Inc., Madison, WI, USA) employing $\omega$ - and $\varphi$ scans. Raw data were processed using APEX 3 (Version 2016.5-0, Bruker AXS Inc., Madison, WI, USA) and SAINT (Version 8.37A, Bruker AXS Inc., 
Madison, WI, USA), corrections for absorption effects were applied using SADABS (Bruker AXS Inc., Madison, WI, USA, [51]). The structures were solved by direct methods and refined against all data by full-matrix least-squares methods on $\mathrm{F}^{2}$ using SHELXTL [52,53] and SHELXLE [54]. Further details of the refinement and crystallographic data are listed in Table S4.1 (Supplementary Materials) and in the below mentioned CIF files. CCDCs 1817852 and 1817853 contain the supplementary crystallographic data for this paper. These data can be obtained free of charge from The Cambridge Crystallographic Data Centre via www.ccdc.cam.ac.uk/data_request/cif.

\subsection{Synthesis of $\mathrm{Tb}\left(\mathrm{AlMe}_{4}\right)_{3}\left(2^{\mathrm{Tb}}\right)$}

Homoleptic $2^{\mathrm{Tb}}$ was synthesized according to the literature from $\mathrm{TbCl}_{3}(\text { thf })_{1.66}[4,11-13,20-23]$. The chloride precursor was obtained via Soxhlet extraction of anhydrous $\mathrm{TbCl}_{3}(5.00 \mathrm{~g}, 18.8 \mathrm{mmol})$ in THF at $100{ }^{\circ} \mathrm{C}$ for $7 \mathrm{~d}$, yielding $49 \%$ of the thf adduct. To a slurry of $\mathrm{TbCl}_{3}(\text { thf })_{1.66}(3.514 \mathrm{~g}, 9.128 \mathrm{mmol})$ in THF $(40 \mathrm{~mL})$ was added $\mathrm{LiNMe}_{2}(1.397 \mathrm{~g}, 27.384 \mathrm{mmol})$ and the mixture was stirred for $1 \mathrm{~d}$. Thereafter the solvent was removed under vacuum and $40 \mathrm{~mL}$ of $n$-hexane as well as $\mathrm{AlMe}_{3}(5.915 \mathrm{~g}$, $82.152 \mathrm{mmol}$ ) were added subsequently. After stirring for another day at ambient temperature, solid side products (e.g., $\mathrm{LiCl}$ ) were removed by centrifugation and filtration and the solvent and by-product $\left(\mathrm{Me}_{2} \mathrm{AlNMe}_{2}\right)_{2}$ were removed under vacuum. Homoleptic $\mathbf{2}^{\mathrm{Tb}}$ was recrystallized three times from $n$-hexane $\left(-35{ }^{\circ} \mathrm{C}\right.$, total crystallized yield $\left.1.38 \mathrm{~g}, 3.29 \mathrm{mmol}, 36 \%\right) .{ }^{27} \mathrm{Al} \mathrm{NMR}\left(130 \mathrm{MHz}, \mathrm{C}_{6} \mathrm{D}_{6}, 26{ }^{\circ} \mathrm{C}\right)$ : $\delta=-203.3 \mathrm{ppm}$. Elemental analysis calcd (\%) for $\mathrm{C}_{12} \mathrm{H}_{36} \mathrm{Al}_{3} \mathrm{~Tb}$ (420.28): $\mathrm{C} 34.29, \mathrm{H}$ 8.63; found: $\mathrm{C} 33.88$, H 9.11 .

\subsection{New Protocol for the Synthesis of $\mathrm{Lu}\left(\mathrm{AlMe}_{4}\right)_{3}\left(2^{\mathrm{Lu}}\right)$}

In a $100 \mathrm{~mL}$ Schlenk flask, $\mathrm{LuCl}_{3}(\mathrm{thf})_{3}(4.97 \mathrm{~g}, 10.0 \mathrm{mmol})$ was dissolved in THF $(30 \mathrm{~mL})$ and methyllithium $(1.32 \mathrm{~g}, 60.0 \mathrm{mmol})$ was added under vigorous stirring. After $24 \mathrm{~h}$, the solvent was removed under vacuum, the residue redissolved in toluene $(10 \mathrm{~mL})$ and the $\mathrm{LiCl}$ was removed via centrifugation and filtration. The toluene solution was evaporated in vacuo and the crude $\left[\mathrm{LuMe}_{3}(\mathrm{MeLi})_{3}(\mathrm{thf})_{\mathrm{x}}\right]$ was suspended in $n$-hexane $(15 \mathrm{~mL})$. Trimethylaluminum $(8.64 \mathrm{~g}, 120.0 \mathrm{mmol})$ was added, the reaction mixture was stirred for $24 \mathrm{~h}$ and $\mathrm{LiAlMe}_{4}$ was separated via filtration. Homoleptic $2^{\mathbf{L u}}$ crystallized from a saturated $n$-hexane solution at $-35^{\circ} \mathrm{C}(2.55 \mathrm{~g}, 5.84 \mathrm{mmol}, 58 \%)$. ${ }^{1} \mathrm{H}$ NMR $\left.\left(400 \mathrm{MHz}, \mathrm{C}_{6} \mathrm{D}_{6}, 26{ }^{\circ} \mathrm{C}\right): \delta=-0.19\left(\mathrm{~s}, 36 \mathrm{H}, \mathrm{AlCH}_{3}\right) \mathrm{ppm} .{ }^{13} \mathrm{C}_{1}{ }^{1} \mathrm{H}\right\} \mathrm{NMR}\left(100 \mathrm{MHz}, \mathrm{C}_{6} \mathrm{D}_{6}\right.$, $26^{\circ} \mathrm{C}$ ): $\delta=3.7 \mathrm{ppm}$; elemental analysis calcd (\%) for $\mathrm{C}_{12} \mathrm{H}_{36} \mathrm{Al}_{3} \mathrm{Lu}$ (436.33): $\mathrm{C} 33.03$, $\mathrm{H}$ 8.32; found: C $33.08, \mathrm{H} 8.61$.

\subsection{Polymerization of Isoprene}

A detailed polymerization procedure is described as a typical example (Table S1.2.4, run 1). $\left[\mathrm{Ph}_{3} \mathrm{C}\right]\left[\mathrm{B}\left(\mathrm{C}_{6} \mathrm{~F}_{5}\right)_{4}\right](\mathrm{A})(18.2 \mathrm{mg}, 0.02 \mathrm{mmol})$ was added to a solution of $2^{\mathrm{Nd}}(8.1 \mathrm{mg}, 0.02 \mathrm{mmol})$ in toluene $(8 \mathrm{~mL})$ and the mixture was aged at ambient temperature for $30 \mathrm{~min}$. After the addition of isoprene $(1.36 \mathrm{~g}, 20 \mathrm{mmol})$, the polymerization was carried out at $25^{\circ} \mathrm{C}$ for $1 \mathrm{~h}$. The reaction was terminated by pouring the polymerization mixture into $25 \mathrm{~mL}$ of methanol containing $0.1 \%(w / w)$ 2,6-di-tert-butyl-4-methylphenol as a stabilizer and stirred for $1 \mathrm{~h}$. The polymer was washed with methanol and dried under vacuum at ambient temperature to constant weight.

Liquid cocatalysts (D and $\mathbf{E}$ ) were added as $1 \mathrm{~mL}$ of a solution of a concentration of 1 equiv. $/ \mathrm{mL}$. The amount of additional solvent applied was then reduced by $1 \mathrm{~mL}$ compared to the procedure given above in order to ensure highest possible similarity regarding the rheological properties of the polymerization mixture.

\subsection{Polymerization of 1,3-Butadiene}

A detailed polymerization procedure is described as a typical example (Table S1.6.3, run 1). $\left[\mathrm{Ph}_{3} \mathrm{C}\right]\left[\mathrm{B}\left(\mathrm{C}_{6} \mathrm{~F}_{5}\right)_{4}\right](\mathbf{A})(18.2 \mathrm{mg}, 0.02 \mathrm{mmol})$ was added to a solution of $2^{\mathrm{Pr}}(8.05 \mathrm{mg}, 0.02 \mathrm{mmol})$ 
in toluene $(28 \mathrm{~mL})$ and the mixture was aged at ambient temperature for $30 \mathrm{~min}$. The mixture was poured into an evacuated 50-mL Büchi miniclave and $1440 \mathrm{~mL}$ (60 mmol) of 1,3-butadiene were added at $90 \mathrm{mLn} / \mathrm{min}$ under constant stirring at $100 \mathrm{rpm}$. The polymerization was carried out at $25{ }^{\circ} \mathrm{C}$ for $1 \mathrm{~h}$. After release of the remaining monomer pressure, if any, the reaction was terminated by pouring the polymerization mixture into $200 \mathrm{~mL}$ of methanol containing $0.1 \%(w / w)$ 2,6-di-tert-butyl-4-methylphenol as a stabilizer and stirred for $1 \mathrm{~h}$. The polymer was washed with methanol and dried under vacuum at ambient temperature to constant weight.

Liquid cocatalysts (D and $\mathbf{E}$ ) were added as $1 \mathrm{~mL}$ of a solution of a concentration of 1 equiv. $/ \mathrm{mL}$. The amount of additional solvent applied was then reduced by $1 \mathrm{~mL}$ compared to the procedure given above in order to ensure highest possible similarity regarding the rheologic properties of the polymerization mixture.

\subsection{Polymerization of Ethylene}

A detailed polymerization procedure is described as a typical example (Table S1.8.1, run 1). $\mathrm{Et}_{2} \mathrm{AlCl}(\mathrm{E})\left(3 \mathrm{~mL}\right.$ of a solution of $0.02 \mathrm{~mol} / \mathrm{L}$ in toluene, 1 equiv.) was added to a solution of $2^{\mathrm{Nd}}$ $(24.3 \mathrm{mg}, 0.06 \mathrm{mmol})$ in toluene $(25 \mathrm{~mL})$ and the mixture was aged at ambient temperature for $30 \mathrm{~min}$. The mixture was poured into an evacuated 300-mL Parr autoclave, $100 \mathrm{~mL}$ toluene and $2100 \mathrm{mLn}$ (60 mmol) of ethylene were added at a maximum flow rate of $450 \mathrm{mLn} / \mathrm{min}$ under constant stirring at $50 \mathrm{rpm}$. The polymerization was carried out at $60^{\circ} \mathrm{C}$ for $1 \mathrm{~h}$. After release of the remaining monomer pressure, if any, the reaction was terminated by pouring the polymerization mixture into $200 \mathrm{~mL}$ of methanol and stirred for $1 \mathrm{~h}$. The polymer was washed with methanol and dried under vacuum at ambient temperature to constant weight.

\subsection{Application of NMR Spectroscopic Techniques for Microstructure Determination}

The microstructures of the polydiene samples produced in this study were evaluated by NMR spectroscopy Previously, the microstructure has been estimated measuring peak heights in the ${ }^{13} \mathrm{C}$ NMR spectra only $[11,13]$. Especially the vinylic content has been underestimated by this method as the variety in tacticity causes wide multiplets and therefore underrepresented peak heights. Furthermore, the nuclear Overhauser effect affects the vinylic and 1,4-polyisoprene signals significantly differently. The ratio of 1,4-/1,2 or 3,4-linkages is obtained from the ${ }^{1} \mathrm{H}$ NMR spectrum by integration of the respective multiplets in the vinylic region of the spectrum (approx. 4.5 to $4.9 \mathrm{ppm}$ for the vinylic linkages and 4.9 to $5.5 \mathrm{ppm}$ for the 1,4-linkages in case of polyisoprene and 4.5 to $5.15 \mathrm{ppm}$ and 5.15 to $6.0 \mathrm{ppm}$, respectively, in case of polybutadiene). The cis/trans ratio of the 1,4-linked part of the polymer is obtained from its ${ }^{13} \mathrm{C}$ NMR spectrum, by integration of the respective methyl (methylene in case of 1,3-butadiene) peaks at 23.5 and $16 \mathrm{ppm}$ in case of isoprene and 27.4 and $32 \mathrm{ppm}$, respectively, in case of 1,3-butadiene. In order to compare integration results in a proton decoupled ${ }^{13} \mathrm{C}$ NMR spectrum, the respective carbon atoms are assumed to be affected by relatively similar nuclear Overhauser effects, as they are decorated with the same number of hydrogen atoms and are located in similar chemical environments [55-58]. For meaningful evaluations, ${ }^{13} \mathrm{C}$ NMR spectra should show a low signal to noise ratio, requiring time-consuming data collection. Another drawback of this method is the fact that paramagnetic Ln ions, that have not been removed in the washing process, cause signal broadening via interaction with the polymer, which results in a loss of accuracy. Therefore, by far less time-consuming ATR-IR techniques have been probed in this study as a pre-screening method.

\subsection{Application of ATR-Infrared Spectroscopic Techniques for Microstructure Detection}

For pre-screening of the microstructure of the obtained polyisoprenes, ATR-IR spectroscopy was applied as a comparative method. NMR spectroscopic data were used for calibration. Hence, the obtained polymer data are considered to be less accurate than NMR-spectroscopy based data sets. But as ATR-IR spectroscopy is by far less costly and time-consuming, its suitability for pre-screening purposes was investigated. To ensure the lowest possible errors of the measurements, the comparative 
algorithm provided by the equipment manufacturer (Thermo Fisher Scientific, Waltham, MA, USA) was calibrated with a large data set of different polyisoprenes mirroring all possible microstructure compositions. In order to determine any deviation, both NMR and ATR-IR spectroscopic data were obtained and compared. Overviewing the findings (Figures S2.1.1-S2.4.1 and Tables S2.1.1-S2.4.1, Supplementary Materials) and considering the errors of the measurements, both methods are in good agreement. The highest individual absolute deviation found in the four series was $7.25 \%$, on average $2.07 \%$. Therefore, ATR-IR spectroscopy can very well serve as a pre-screening method for the microstructures of polyisoprenes. Furthermore, an optimized calibration of the algorithms might provide even more accurate results of wider applicability.

In order to provide an idea of the limits of the applicability of this method, surface manipulation of the polymers was performed by applying UV-light irradiation (Table S1.5.1, Supplementary Materials). Thereafter, the microstructure of the polymer samples was once more investigated by both techniques and compared. For NMR spectroscopy, no significant difference of the data before and after the manipulation was observed. But due to the low penetration depth of the IR-radiation into the polymer samples, in case of the ATR-IR data, such surface manipulation effects on the microstructure are emphasized (Table S2.5.1, Supplementary Materials). The observed shift toward vinylic linkage is supposed to be an artefact and due to an overlap of vibrations in the IR spectrum. UV-induced crosslinking is probably the origin of these new signals.

\section{Conclusions}

Homoleptic lanthanide and yttrium tris(tetramethylaluminate)s $\mathrm{Ln}\left(\mathrm{AlMe}_{4}\right)_{3}(\mathrm{Ln}=\mathrm{La}, \mathrm{Ce}, \mathrm{Pr}$, $\mathrm{Nd}, \mathrm{Gd}, \mathrm{Tb}, \mathrm{Dy}, \mathrm{Ho}, \mathrm{Y}, \mathrm{Er}$, and $\mathrm{Lu}$ ) exhibit exceptional performance in 1,3-diene polymerization. Importantly, the reaction of $\left[\operatorname{LnMe}_{6}\left(\operatorname{Li}(\mathrm{do})_{x}\right)_{3}\right]$ with trimethylaluminum provides a more efficient precatalyst synthesis for the smaller rare-earth metal centers as shown for lutetium.

Due to the different nature of the borate/borane or $\mathrm{R}_{2} \mathrm{AlCl}$ cocatalysts, distinct activation mechanisms occur, all providing individual trends and high-yielding precatalyst/cocatalyst combinations. The highest cis-1,4-contents were found when employing $\mathrm{R}_{2} \mathrm{AlCl}$ cocatalysts and tetramethylaluminate complexes with $\mathrm{Ln}=\mathrm{Ce}, \mathrm{Pr}, \mathrm{Nd}$, and $\mathrm{Gd}$, showing virtually complete cis-1,4-selectivity ( $>99.9 \%$ for $\mathrm{Ln}=\mathrm{Gd}$ with cocatalyst $\left.\mathrm{Me}_{2} \mathrm{AlCl}\right)$. The highest cis-selectivity induced by the borate/borane cocatalysts was found for the combination of $\mathrm{Nd}\left(\mathrm{AlMe}_{4}\right)_{3}$ with 2 equiv. of $\left[\mathrm{B}\left(\mathrm{C}_{6} \mathrm{~F}_{5}\right)_{3}\right]$ $(92.7 \%)$ although the general trend for these systems points to higher cis-selectivities with the smallest lanthanides. The most trans-selective combinations reach medium selectivity $(<60 \%)$ for $\mathrm{Ln}=\mathrm{La}$ and borate/borane cocatalysts. Interestingly, the uniformity of the active systems was best with $\mathrm{Ln}=\mathrm{Ce}$ showing even a PDI $<1.2$ with 2 equiv. of cocatalyst $\left[\mathrm{PhNMe}_{2} \mathrm{H}\right]\left[\mathrm{B}\left(\mathrm{C}_{6} \mathrm{~F}_{5}\right)_{4}\right]$ and a surprisingly low $\mathrm{PDI}$ with $\mathrm{Me}_{2} \mathrm{AlCl}$, in comparison with the generally high PDI for the $\mathrm{R}_{2} \mathrm{AlCl}$-cocatalyzed polymers. Deeper insights into the polymerization performance of the binary system $\mathrm{Nd}\left(\mathrm{AlMe}_{4}\right)_{3} / \mathrm{Et}_{2} \mathrm{AlCl}$ could be gained by screening the pre-reaction time and the cocatalyst concentration. Here, different behaviors for the polymerization of 1,3-butadiene and isoprene were found. While the multimetallic cationic species, proposed in the literature seem to disaggregate upon monomer coordination for the bulkier isoprene, larger agglomerates are suggested to polymerize 1,3-butadiene. Interesting side reactions at high cocatalyst loadings as well as a comparatively high number of polymer chains per catalyst center, including further elucidation of the active species, will be subject to further research. Finally, ATR-IR spectroscopy displays an effective pre-screening method for the microstructures of polyisoprenes.

Supplementary Materials: The following are available online at www.mdpi.com/2073-4344/8/2/61/s1, Supplementary Materials (pdf) containing polymerization and crystal data. CIF files containing crystal data for complexes $2^{\mathrm{Gd}}$ and $\mathbf{2}^{\mathrm{Tb}}$. The latter data have been deposited as well at CCDC (1817852 and 1817853).

Acknowledgments: We are grateful to the German Science Foundation (An238/14-2) and Bridgestone Japan for generous support, as well as Bassem Sabagh, Amy Ross (Malvern Instruments Ltd., Malvern, UK), and Bernd Schäfer (Malvern Instruments Ltd., Herrenberg, Germany) for performing the high temperature GPC measurements. 
Author Contributions: C.O.H. and L.N.J. conceived and designed the experiments; D.D. contributed to the design of the ethylene polymerization experiments; C.O.H., L.N.J., D.D., T.Z. and R.S. performed the experiments; C.O.H., L.N.J., D.D., T.Z. and R.S. analyzed the data; C.M.-M. performed the X-ray structure analyses; C.O.H. wrote the paper; R.A. contributed reagents/materials/analysis tools, supervised all contributions and contributed to writing the paper.

Conflicts of Interest: The authors declare no conflict of interest.

\section{References}

1. Boor, J.J. Ziegler-Natta Catalysts and Polymerizations; Academic Press: New York, NY, USA; San Francisco, CA, USA; London, UK, 1979.

2. Mülhaupt, R. Catalytic Polymerization and Post Polymerization Catalysis Fifty Years After the Discovery of Ziegler's Catalysts. Macromol. Chem. Phys. 2003, 204, 289-327. [CrossRef]

3. Eisch, J.J. Fifty Years of Ziegler-Natta Polymerization: From Serendipity to Science. A Personal Account. Organometallics 2012, 31, 4917-4932. [CrossRef]

4. Fischbach, A.; Anwander, R. Rare-Earth Metals and Aluminum getting Close in Ziegler Type Organometallics. Adv. Polym. Sci. 2006, 204, 155-281.

5. Friebe, L.; Nuyken, O.; Obrecht, W. Neodymium-Based Ziegler/Natta Catalysts and their Application in Diene Polymerization. Adv. Polym. Sci. 2006, 204, 1-154.

6. Porri, L.; Ricci, G.; Giarrusso, A.; Shubin, N.; Lu, Z. Recent Developments in Lanthanide Catalysts for 1,3-Diene Polymerization. In ACS Symposium Series 749-Olefin Polymerization: Emerging Frontiers; Arjunan, P., McGrath, J.C., Hanlon, T., Eds.; Oxford University Press: New York, NY, USA, 2000; pp. 15-30.

7. Osakada, K.; Takeuchi, D. Coordination Polymerization of Dienes, Allenes, and Methylenecycloalkanes. In Polymer Synthesis; Springer: Berlin/Heidelberg, UK, 2004; pp. 137-194.

8. Shen, Z.; Ouyang, J. Handbook on the Physics and Chemistry of Rare Earths; Gschneidner, K.A., Jr., Fleming, L., Eds.; Elsevier Science Publishers: Amsterdam, The Netherlands, 1987; Chapter 61.

9. Taube, R.; Sylvester, G. Applied Homogeneous Catalysis with Organometallic Compounds; Cornils, B., Herrmann, W.A., Eds.; Wiley-VCH: Weinheim, Germany, 2002; pp. 280-318.

10. Zimmermann, M.; Anwander, R. Homoleptic Rare-Earth Metal Complexes Containing Ln-C $\sigma$-Bonds. Chem. Rev. 2010, 110, 6194-6259. [CrossRef] [PubMed]

11. Fischbach, A.; Klimpel, M.G.; Widenmeyer, M.; Herdtweck, E.; Scherer, W.; Anwander, R. Stereospecific Polymerization of Isoprene with Molecular and MCM-48-Grafted Lanthanide(III) Tetraalkylaluminates. Angew. Chem. Int. Ed. 2004, 43, 2234-2239. [CrossRef] [PubMed]

12. Zimmermann, M.; Frøystein, N.Å.; Fischbach, A.; Sirsch, P.; Dietrich, H.M.; Törnroos, K.W.; Herdtweck, E.; Anwander, R. Homoleptic Rare-Earth Metal(III) Tetramethylaluminates: Structural Chemistry, Reactivity, and Performance in Isoprene Polymerization. Chem. Eur. J. 2007, 13, 8784-8800. [CrossRef] [PubMed]

13. Meermann, C.; Törnroos, K.W.; Nerdal, W.; Anwander, R. Rare-Earth Metal Mixed Chloro/Methyl Compounds: Heterogeneous-Homogeneous Borderline Catalysts in 1,3-Diene Polymerization. Angew. Chem. Int. Ed. 2007, 46, 6508-6513. [CrossRef] [PubMed]

14. Fischbach, A.; Perdih, F.; Herdtweck, E.; Anwander, R. Structure-Reactivity Relationships in Rare-Earth Metal Carboxylate-Based Binary Ziegler-Type Catalysts. Organometallics 2006, 25, 1626-1642. [CrossRef]

15. Fischbach, A.; Perdih, F.; Sirsch, P.; Scherer, W.; Anwander, R. Rare-Earth Ziegler-Natta Catalysts: Carboxylate-Alkyl Interchange. Organometallics 2002, 21, 4569-4571. [CrossRef]

16. Arndt, S.; Beckerle, K.; Zeimentz, P.M.; Spaniol, T.P.; Okuda, J. Cationic Yttrium Methyl Complexes as Functional Models for Polymerization Catalysts of 1,3-Dienes. Angew. Chem. Int. Ed. 2005, 44, 7473-7477. [CrossRef] [PubMed]

17. Robert, D.; Spaniol, T.P.; Okuda, J. Neutral and Monocationic Half-Sandwich Methyl Rare-Earth Metal Complexes: Synthesis, Structure, and 1,3-Butadiene Polymerization Catalysis. Eur. J. Inorg. Chem. 2008, 2801-2809. [CrossRef]

18. Litlabø, R.; Lee, H.S.; Niemeyer, M.; Törnroos, K.W.; Anwander, R. Rare-Earth metal bis(tetramethylaluminate) complexes supported by a sterically crowded triazenido ligand. Dalton Trans. 2010, 39, 6815-6825. [CrossRef] [PubMed] 
19. Occhipinti, G.; Meermann, C.; Dietrich, H.M.; Litlabø, R.; Auras, F.; Törnroos, K.W.; Maichle-Mössmer, C.; Jensen, V.R.; Anwander, R. Synthesis and Stability of Homoleptic Metal(III) Tetramethylaluminates. J. Am. Chem. Soc. 2011, 133, 6323-6337. [CrossRef] [PubMed]

20. Nieland, A.; Mix, A.; Neumann, B.; Stammler, H.G.; Mitzel, N.W. Lanthanoid Tetramethylaluminates and Their Paramagnetic NMR Parameters. Eur. J. Inorg. Chem. 2014, 51-57. [CrossRef]

21. Evans, W.J.; Anwander, R.; Ziller, J.W. Inclusion of $\mathrm{Al}_{2} \mathrm{Me}_{6}$ in the Crystalline Lattice of the Organometallic Complexes $\mathrm{LnAl}_{3} \mathrm{Me}_{12}$. Organometallics 1995, 14, 1107-1109. [CrossRef]

22. König, S.N.; Chilton, N.F.; Maichle-Mössmer, C.; Pineda, E.M.; Pugh, T.; Anwander, R.; Layfield, R.A. Fast magnetic relaxation in an octahedral dysprosium tetramethyl-aluminate complex. Dalton Trans. 2014, 43, 3035-3038. [CrossRef] [PubMed]

23. Klooster, W.T.; Lu, R.S.; Anwander, R.; Evans, W.J.; Koetzle, T.F.; Bau, R. Neutron Diffraction Study of $\left[\mathrm{Nd}\left(\mathrm{AlMe}_{4}\right)_{3}\right] \quad 0.5 \mathrm{Al}_{2} \mathrm{Me}_{6}$ at $100 \mathrm{~K}$ : The First Detailed Look at a Bridging Methyl Group with a Trigonal-Bipyramidal Carbon Atom. Angew. Chem. Int. Ed. 1998, 37, 1268-1270. [CrossRef]

24. Dietrich, H.M.; Raudaschl-Sieber, G.; Anwander, R. Trimethylyttrium and Trimethyllutetium. Angew. Chem. Int. Ed. 2005, 44, 5303-5306. [CrossRef] [PubMed]

25. Schumann, H.; Mueller, J.; Bruncks, N.; Lauke, H.; Pickardt, J.; Schwarz, H.; Eckart, K. Organometallic compounds of the lanthanides. Part 17. Tris[(tetramethylethylenediamine)lithium] hexamethyl derivatives of the rare earths. Organometallics 1984, 3, 69-74. [CrossRef]

26. Schumann, H.; Müller, J. Tris[( $N, N, N^{\prime}, N^{\prime}$-tetramethylethylenediamine)lithium $]$ hexamethylerbate(III) and -lutetate(III). Angew. Chem. Int. Ed. 1978, 17, 276. [CrossRef]

27. Schumann, H.; Pickardt, J.; Bruncks, N. Crystal and Molecular Structure of $[\operatorname{Li}(\operatorname{tmen})]_{3}\left[\operatorname{Er}\left(\mathrm{CH}_{3}\right)_{6}\right]$. Angew. Chem. Int. Ed. 1981, 20, 120-121. [CrossRef]

28. Shannon, R.D.; Prewitt, C.T. Effective Ionic Radii in Oxides and Fluorides. Acta Cryst. 1969, B25, 925-946. [CrossRef]

29. Shannon, R.D. Revised Effective Ionic Radii and Systematic Studies of Interatomic Distances in Halides and Chalcogenides. Acta Cryst. 1976, A32, 751-767. [CrossRef]

30. Chen, E.Y.-X.; Marks, T.J. Cocatalysts for Metal-Catalyzed Olefin Polymerization: Activators, Activation Processes, and Structure-Activity Relationships. Chem. Rev. 2000, 100, 1391-1434. [CrossRef] [PubMed]

31. Bonath, M.; Hollfelder, C.O.; Schädle, D.; Maichle-Mössmer, C.; Sirsch, P.; Anwander, R. C-H Bond Activation and Isoprene Polymerization by Lutetium Alkylaluminate/gallate Complexes Bearing a Peripheral Boryl and a Bulky Hydridotris(pyrazolyl)borato Ligand. Eur. J. Inorg. Chem. 2017, 4683-4692. [CrossRef]

32. Diether, D.; Tyulyunov, K.; Maichle-Mössmer, C.; Anwander, R. Fluorenyl Half-Sandwich Bis(tetramethylaluminate) Complexes of the Rare-Earth Metals: Synthesis, Structure, and Isoprene Polymerization. Organometallics 2017, 36, 4649-4659. [CrossRef]

33. Monteil, V.; Spitz, R.; Boisson, C. Polymerization of butadiene and copolymerization of butadiene with styrene using neodymium amide catalysts. Polym. Int. 2004, 53, 576-581. [CrossRef]

34. Dietrich, H.M.; Schuster, O.; Törnroos, K.W.; Anwander, R. Heterobimetallic Half-Lanthanidocene Clusters: Novel Mixed Tetramethylaluminato/Chloro Coordination. Angew. Chem. Int. Ed. 2006, 45, 4858-4863. [CrossRef] [PubMed]

35. Evans, W.J.; Champagne, T.M.; Giarikos, D.G.; Ziller, J.W. Lanthanide Metallocene Reactivity with Dialkyl Aluminum Chlorides: Modeling Reactions Used to Generate Isoprene Polymerization Catalysts. Organometallics 2005, 24, 570-579. [CrossRef]

36. Evans, W.J.; Champagne, T.M.; Ziller, J.W. An Ethyl Aluminum Oxide (EAO) Complex with $\mu-\eta^{1}: \eta^{2}$-Ethyl Coordination Derived from a Samarocene Carboxylate and Triethylaluminum. Organometallics 2005, 24, 4882-4885. [CrossRef]

37. Hayes, P.G.; Piers, W.E.; Parvez, M. Cationic Organoscandium $\beta$-Diketiminato Chemistry: Arene Exchange Kinetics in Solvent Separated Ion Pairs. J. Am. Chem. Soc. 2003, 125, 5622-5623. [CrossRef] [PubMed]

38. Yu, N.; Nishiura, M.; Li, X.; Xi, Z.; Hou, Z. Cationic Scandium Allyl Complexes Bearing Mono(cyclopentadienyl) Ligands: Synthesis, Novel Structural Variety, and Olefin Polymerization Catalysis. Chem. Asian J. 2008, 3, 1406-1414. [CrossRef] [PubMed]

39. Tardif, O.; Kaita, S. Generation of cationic indenyl silylamide gadolinium and scandium complexes $\left[(\mathrm{Ind}) \mathrm{Ln}\left\{\mathrm{N}\left(\mathrm{SiMe}_{3}\right)_{2}\right\}\right]^{+}\left[\mathrm{B}\left(\mathrm{C}_{6} \mathrm{~F}_{5}\right)_{4}\right]^{-}$and their reactivity for 1,3-butadiene polymerization. Dalton Trans. 2008, 2531-2533. [CrossRef] [PubMed] 
40. Lei, Y.; Su, Q.; Chen, J.; Luo, Y. Synthesis, characterization of cationic half-sandwich scandium mono(silylamide) complexes and their unexpected reactivity toward $\mathrm{C}-\mathrm{Cl} \sigma$ bond activation of chlorobenzene. J. Organomet. Chem. 2014, 769, 119-123. [CrossRef]

41. Zimmermann, M.; Törnroos, K.W.; Anwander, R. Cationic Rare-Earth-Metal Half-Sandwich Complexes for the Living trans-1,4-Isoprene Polymerization. Angew. Chem. Int. Ed. 2008, 47, 775-778. [CrossRef] [PubMed]

42. Tobisch, S.; Bögel, H.; Taube, R. Mechanistic Studies of the 1,4-Cis Polymerization of Butadiene According to the $\pi$-Allyl Insertion Mechanism. 1. Density Functional Study of the $\mathrm{C}-\mathrm{C}$ Bond Formation Reaction in Cationic $\left(\eta^{3}\right.$-Allyl) $\left(\eta^{2}-/ \eta^{4}\right.$-butadiene)nickel(II) Complexes $\left[\mathrm{Ni}\left(\mathrm{C}_{3} \mathrm{H}_{5}\right)\left(\mathrm{C}_{4} \mathrm{H} 6\right)\right]^{+}$and $\left[\mathrm{Ni}\left(\mathrm{C}_{3} \mathrm{H}_{5}\right)\left(\mathrm{C}_{4} \mathrm{H}_{6}\right)\left(\mathrm{C}_{2} \mathrm{H}_{4}\right)\right]^{+}$. Organometallics 1996, 15, 3563-3571.

43. Taube, R.; Windisch, H.; Maiwald, S. The catalysis of the stereospecific butadiene polymerization by Allyl Nickel and Allyl Lanthanide complexes-A mechanistic comparison. Macromol. Symp. 1995, 89, 393-409. [CrossRef]

44. Ward, B.D.; Bellemin-Laponnaz, S.; Gade, L.H. $C_{3}$ Chirality in Polymerization Catalysis: A Highly Active Dicationic Scandium(III) Catalyst for the Isoselective Polymerization of 1-Hexene. Angew. Chem. Int. Ed. 2005, 44, 1668-1671. [CrossRef] [PubMed]

45. Arndt, S.; Spaniol, T.P.; Okuda, J. Homogeneous Ethylene-Polymerization Catalysts Based on Alkyl Cations of the Rare-Earth Metals: Are Dicationic Mono(alkyl) Complexes the Active Species? Angew. Chem. Int. Ed. 2003, 42, 5075-5079. [CrossRef] [PubMed]

46. Dettenrieder, N.; Hollfelder, C.O.; Jende, L.N.; Maichle-Mössmer, C.; Anwander, R. Half-Sandwich Rare-Earth-Metal Alkylaluminate Complexes Bearing Peripheral Boryl Ligands. Organometallics 2014, 33, 1528-1531. [CrossRef]

47. Valente, A.; Mortreux, A.; Visseaux, M.; Zinck, P. Coordinative Chain Transfer Polymerization. Chem. Rev. 2013, 113, 3836-3857. [CrossRef] [PubMed]

48. Brintzinger, H.H.; Fischer, D.; Mülhaupt, R.; Rieger, B.; Waymouth, R.M. Stereospecific Olefin Polymerization with Chiral Metallocene Catalysts. Angew. Chem. Int. Ed. 1995, 34, 1143-1170. [CrossRef]

49. Rocha, T.C.J.; Coutinho, F.M.B.; Soares, B.G. Effect of alkylaluminum structure on Ziegler-Natta catalyst systems based on neodymium for producing high-cis polybutadiene. Polym. Bull. 2009, 62, 1-10. [CrossRef]

50. Hagihara, H.; Shiono, T.; Ikeda, T. Stereospecificity of propene polymerization with achiral titanocene-based catalysts. Macromol. Chem. Phys. 1998, 199, 2439-2444. [CrossRef]

51. Krause, L.; Herbst-Irmer, R.; Sheldrick, G.M.; Stalke, D. Comparison of silver and molybdenum microfocus X-ray sources for single-crystal structure determination. J. Appl. Cryst. 2015, 48, 3-10. [CrossRef] [PubMed]

52. Sheldrick, G.M. SHELXT-Integrated space-group and crystal-structure determination. Acta Cryst. 2015, A71, 3-8. [CrossRef] [PubMed]

53. Sheldrick, G.M. Crystal structure refinement with Shelxl. Acta Cryst. 2015, C71, 3-8.

54. Hubschle, C.B.; Sheldrick, G.M.; Dittrich, B. ShelXle: A Qt graphical user interface for SHELXL. J. Appl. Crystallogr. 2011, 44, 1281-1284. [CrossRef] [PubMed]

55. Elgert, K.-F.; Quack, G.; Stützel, B. Zur Struktur des Polybutadiens, 3. Das ${ }^{13}$ C-NMR-Spektrum des cis-1,4-1,2-polybutadiens. Makromol. Chem. 1975, 176, 759-765. [CrossRef]

56. Elgert, K.-F.; Quack, G.; Stützel, B. Zur Struktur des Polybutadiens, 2. Das ${ }^{13}$ C-NMR-Spektrum des 1,2-polybutadiens. Makromol. Chem. 1974, 175, 1955-1960. [CrossRef]

57. Elgert, K.-F.; Stützel, B.; Frenzel, P.; Cantow, H.-J.; Streck, R. Zur Struktur des Polybutadiens, 1. Das ${ }^{13}$ C-NMR-Spektrum der 1,4-Polybutadiene. Makromol. Chem. 1973, 170, 257-260. [CrossRef]

58. Santee, E.R.; Chang, R.; Morton, M. $300 \mathrm{MHz}$ proton NMR of polybutadiene: Measurement of cis-trans isomeric content. J. Polym. Sci. Polym. Lett. Ed. 1973, 11, 449-452. [CrossRef]

(C) 2018 by the authors. Licensee MDPI, Basel, Switzerland. This article is an open access article distributed under the terms and conditions of the Creative Commons Attribution (CC BY) license (http:/ / creativecommons.org/licenses/by/4.0/). 